\title{
MONITORAMENTO DO SISTEMA DE MANEJO DA CANA-DE-AÇÚCAR NAS MICRORREGIÕES DO TRIÂNGULO MINEIRO E ALTO PARANAÍBA, MINAS GERAIS, BRASIL (2015-2017)
}

\author{
Bruna Aparecida Silva Dias \\ Doutoranda em Geografia pelo Programa de Pós-graduação em Geografia, Instituto de Geografia da \\ Universidade Federal de Uberlândia (PPGEO/IG/UFU), Uberlândia-MG, Brasil \\ brunadias@ufu.br
}

\begin{abstract}
Jussara dos Santos Rosendo
Profa. Dra. do curso de Geografia e do Programa de Pós-graduação em Geografia do Pontal, Instituto de Ciências Humanas do Pontal da Universidade Federal de Uberlândia (PPGEP/ICHPO/UFU), Ituiutaba-MG, Brasil jussara.rosendo@ufu.br
\end{abstract}

\section{RESUMO}

No processo de produção da cana-de-açúcar, a colheita é a etapa que mais passa por alterações tecnológicas em razão das exigências socioambientais e econômicas. Por isso, o Brasil nas últimas décadas tem apostado em novas tecnologias para se enquadrar nos padrões exigidos pelo mercado, que incluiu principalmente a eliminação do uso do fogo na pré-colheita da cana-de-açúcar em razão dos poluentes emitidos na atmosfera com a prática. Nesta perspectiva, este trabalho teve como objetivo diagnosticar a área cultivada com canade-açúcar e identificar o sistema de manejo do corte com e/ou sem o emprego do fogo na mesorregião do Triângulo Mineiro e Alto Paranaíba (TMAP) nos anos de 2015 e 2017. A metodologia da pesquisa consistiu em mapear a cana-de-açúcar tendo como base o ano 2015 e monitorar essas áreas no ano 2017, por meio da utilização de imagens de satélite multitemporais no período correspondente à colheita da cana (abril a outubro). Os resultados da pesquisa permitiram concluir que houve redução de $28,3 \%$ na área total colhida com canade-açúcar (mecanizada e queimada) no TMAP no período analisado. Quanto ao sistema de manejo da colheita da cana nas microrregiões do TMAP, nos anos de 2015 e 2017, suas análises comprovam que o corte mecanizado é superior (91,0\% em 2015, e 79,0\% em 2017) ao emprego do fogo $(9,0 \%$ em 2015 , e $21,0 \%$ em 2017), embora tenha sido constatado um aumento significativo na área queimada em 2017. As microrregiões de Frutal e Uberaba possuem as maiores áreas colhidas, seguidas de Uberlândia, Ituiutaba e Araxá. Por outro lado, as de Patos de Minas e Patrocínio não apresentaram áreas plantadas ou estimativas de produção relevantes. Em todas as microrregiões houve redução da área mecanizada e incremento das queimadas, com destaque para Frutal, que perdeu 83.929 ha de colheita mecanizada, ao mesmo tempo em que ocorreu aumento de 10.976 ha no uso do fogo, ficando atrás apenas de Ituiutaba, cujo saldo de 11.588 ha foi observado. Em termos absolutos, a microrregião de Uberaba é a que possui a maior extensão de cana queimada, ao todo foram 23.768 ha, em 2015, e 31.933 ha, em 2017, o que representou um incremento de 8.165 ha.

Palavras-chave: Cana-de-açúcar. Sistema de manejo. Sensoriamento remoto.

\section{MONITORING THE SUGARCANE MANAGEMENT SYSTEM IN THE MICROREGIONS KNOWN AS TRIÂNGULO MINEIRO AND ALTO PARANAÍBA, MINAS GERAIS, BRAZIL (2015-2017)}

\begin{abstract}
In the sugar cane production process, due to socio-environmental and the economics behind it, sugarcane harvesting is the stage required to undergo significant technological changes. Therefore, for the last decades Brazil has invested in new technologies to meet the market standards, which basically consist of using no fire during pre-harvest as it only emits pollutants into the atmosphere. From that perspective, this work aims to diagnose the area where sugarcane is cultivated and to identify the cutting process system used with or without the use of fire in the mesoregion known as Triângulo Mineiro e Alto Paranaíba (TMAP) in 2015 and 2017. The research methodology consisted of mapping sugar cane based on the year 2015 and monitoring these areas in the year 2017, using multitemporal satellite images during the
\end{abstract}




\begin{abstract}
period corresponding to the cane harvest (April to October). The results of the research allowed the following conclusion: there was a reduction of $28.3 \%$ in the total area harvested with sugarcane (mechanized and burned) in TMAP in the analyzed period. As for the sugarcane harvest management system in the micro-regions of TMAP, in the years 2015 and 2017 , the analyzes show that mechanized cutting is superior $(91.0 \%$ in 2015 , and $79.0 \%$ in 2017 ) to the use of fire. $(9.0 \%$ in 2015 , and $21.0 \%$ in 2017$)$, although there was a significant increase in the burned area in 2017. The Frutal and Uberaba microregions have the largest harvested areas, followed by Uberlândia, Ituiutaba and Araxá. On the other hand, as for Patos de Minas and Patrocínio, they did not present planted areas or sufficient relevant production. In all microregions there was a reduction in the mechanized area and an increase in fires, especially Frutal, which lost 83,929 ha of its mechanized harvesting, while there was an increase of 10,976 ha in the use of fire, second only to Ituiutaba, whose balance 11,588 ha was observed. In absolute terms, the microregion Uberaba has the largest amount of burnt cane, in all there were 23,768 ha in 2015 and 31,933 ha in 2017 , which represented an increase of 8,165 ha.
\end{abstract}

Keywords: Sugarcane. Management system. Remote sensing.

\title{
INTRODUÇÃO
}

A escolha do tipo de colheita da cana-de-açúcar pode influenciar nos mais variados aspectos da produção, como atributos químicos, físicos e biológicos do solo, o meio ambiente, o ar e na duração da cultura. Por muitos anos, o emprego do fogo foi utilizado como método despalhador e facilitador do corte, todavia, a prática tem sido condenada (e extinta) em razão dos protocolos e exigências ambientais presentes no país e/ou nações que exportam o produto brasileiro.

Um exemplo disso é a Deliberação Normativa do Conselho Estadual de Política Ambiental (COPAM), n¹33 de 2009, do Estado de Minas Gerais, que regulamentou a eliminação da queimada nos canaviais mineiros até o ano de 2014. Entretanto, dados da CONAB (2017) estimaram que em 0,5\% da área do total do estado a cana-de-açúcar ainda é queimada.

A substituição gradual do emprego do fogo, e consequentemente do corte manual, associada ao aumento na mecanização da colheita, foram mudanças importantes no processo produtivo, que visaram garantir a sustentabilidade e o atendimento às exigências ambientais do mercado no setor sucroenergético.

Concentrando a maior produção canavieira do Brasil, a região Centro-Sul tem como os principais produtores os Estados de São Paulo, Goiás, Minas Gerais, Mato Grosso do Sul e Paraná, que juntos representam mais de $86 \%$ do total da área cultivada no país.

Minas Gerais é o segundo maior estado produtor de cana-de-açúcar do país. Dados da Secretaria de Estado de Agricultura, Pecuária e Abastecimento- Seapa (2017) demonstraram que a produção totalizou 72,53 mil toneladas, correspondendo a $10,2 \%$ da participação relativa do estado no setor sucroenergético, perdendo apenas para São Paulo, com 382.176,0 mil toneladas e com 54\% da participação na produção brasileira. Das mesorregiões mineiras, a do TMAP ocupa o primeiro lugar em área plantada ou destinada à colheita, totalizando 637.268 ha, seguido pela mesorregião Noroeste com 57.189 ha e Sul/Sudeste com 51.339 ha (IBGE, 2016).

A presente pesquisa teve como principal objetivo diagnosticar a área cultivada com cana-de-açúcar e identificar o sistema de manejo do corte com e/ou sem o emprego do fogo na mesorregião do Triângulo Mineiro e Alto Paranaíba (TMAP) nos anos de 2015 e 2017.

\section{METODOLOGIA}

\section{Área de estudo}

A mesorregião do TMAP localiza-se, aproximadamente, entre os paralelos $17^{\circ} 55^{\prime} 12^{\prime \prime}$ e $20^{\circ} 41^{\prime} 30^{\prime \prime} \mathrm{S}$

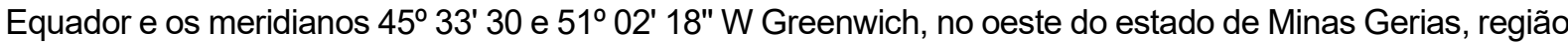
Sudeste do Brasil, e possui uma área territorial de 9.054 .005 ha. A localização geográfica da área de estudo é mostrada na Figura 1: 
Figura 1 - Localização da mesorregião do TMAP nos contextos nacional, mineiro e de suas microrregiões.
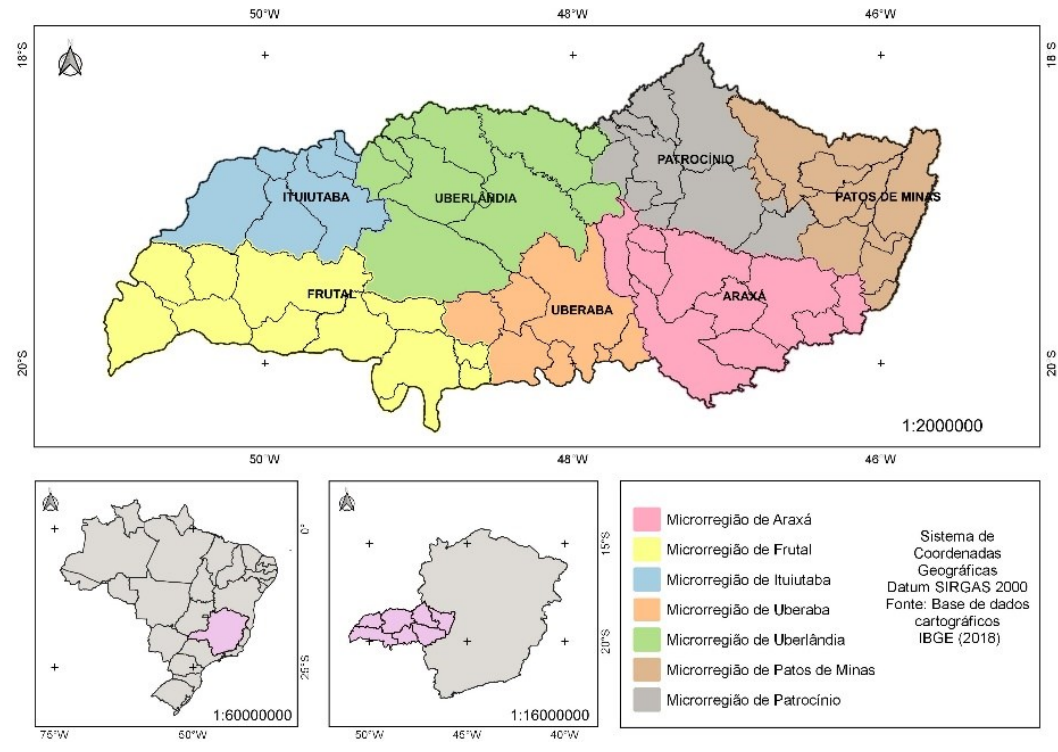

Fonte - da Autora, 2019.

Conhecida pela agroindústria mais moderna do estado, a mesorregião do TMAP é considerada uma área de fronteira agrícola. Os principais cultivos comerciais são soja, milho e cana-de-açúcar, além da criação do rebanho bovino de alto valor comercial e indústria de fertilizantes. Composta por 66 municípios distribuídos em sete microrregiões (Ituiutaba, Frutal, Uberlândia, Uberaba, Patrocínio, Araxá e Patos de Minas), é a segunda maior mesorregião do estado em área territorial e em população (2.296.246 habitantes) (IBGE, 2017).

\section{Materiais}

Com o objetivo de alcançar os resultados deste trabalho, os seguintes materiais foram utilizados:

1) Mapeamento do sistema de manejo da colheita da cana-de-açúcar mediante uso do fogo (ano base 2015), realizado por meio de classificação automática de imagens multitemporais Landsat-like, disponibilizado por Dias (2017);

2) Imagens do sensor OLI/Landsat8 adquiridas no período de abril a outubro de 2017, sendo necessárias 8 imagens para recobrir toda mesorregião por mês, de acordo com o arquivo vetorial da órbita/ponto no sítio digital do INPE.

Quadro 1 - Características do sensor OLI/Landsat8.

\begin{tabular}{|c|c|c|c|}
\hline Sensor/Satélite & Órbita/Ponto & Resolução espacial & Bandas \\
\hline \multirow{8}{*}{ OLI/Landsat8 } & $222 / 73$ & \multirow{8}{*}{$30 \mathrm{~m}$} & \multirow{8}{*}{$\begin{array}{c}\text { Banda } 4(0,636-0,673 \mu \mathrm{m}) \\
\text { Banda } 5(0,851- \\
0,879 \mu \mathrm{m}) \\
\text { Banda } 6(1,566- \\
1,651 \mu \mathrm{m})\end{array}$} \\
\hline & $222 / 74$ & & \\
\hline & $221 / 73$ & & \\
\hline & $221 / 74$ & & \\
\hline & $220 / 73$ & & \\
\hline & $220 / 74$ & & \\
\hline & $219 / 73$ & & \\
\hline & $219 / 74$ & & \\
\hline
\end{tabular}

3) Imagens fração/componentes cana-de-açúcar queimada, cana-de-açúcar crua e cana-de-açúcar verde geradas pelo método Modelo Linear de Mistura Espectral (MLME) descrito por Shimabukuro (2017).

4) Produto S5-TOC-NDVI (Global 5-daily composites, Top-Of-Canopy, Normalized Difference Vegetation Index band) do PROBA-V, utilizado para melhorar a resolução temporal dos dados de sensoriamento remoto. Os dados foram extraídos do website

$\begin{array}{lllll}\text { Caminhos de Geografia } & \text { Uberlândia-MG } & \text { v. 21, n. } 77 & \text { Out/2020 } & \text { p. 263-282 Página } 265\end{array}$


(http://www.vitoeodata.be/PDF/portal/Application.html). Esse produto é composto a cada cinco dias com pixels livres de nuvens e resolução espacial de $100 \mathrm{~m}$. Foi montada uma série temporal de imagens, datadas de 01 de janeiro de 2017 a 31 de dezembro de 2017;

5) Arquivos vetoriais da mesorregião e dos municípios que a compõem, disponibilizados pelo IBGE (https://downloads.ibge.gov.br/downloads_geociencias.htm) utilizados em todos os procedimentos de recorte da área estudada.

\section{PROCEDIMENTOS METODOLÓGICOS}

\section{Pré-processamento}

O mapa das áreas cultivadas com cana-de-açúcar para o ano de 2015 foi disponibilizado por Dias (2017), tendo sido realizado por classificação automática de imagens multitemporais de sensores remotos. Quanto aos dados de 2017, o pré-processamento consistiu na obtenção do mosaico das cenas do sensor OLI/Landsat8 com resolução espacial de 30 metros e com a menor cobertura de nuvens possível dentro do período analisado (de abril a outubro, pois são os meses em que a colheita é realizada, coincidindo com o período da seca na região). Para isso, foram executadas a composição colorida, o mosaico e o recorte da área de interesse.

Na primeira etapa, as imagens foram adquiridas em Nível 2 (reflectância de superfície), ou seja, já passaram pelo processo de correção atmosférica, explicada por Sanches et al. (2011, p. 7564) como a correção atmosférica de imagens de satélite é feita com a intenção de minimizar os efeitos atmosféricos na radiância de uma cena, visto que a atmosfera, por causa dos fenômenos de espalhamento, absorção e refração da energia eletromagnética, afeta a radiância refletida pela superfície que é captada pelo sensor.

Foram utilizadas as bandas 4 (Red- 0,64-0,67 $\mu \mathrm{m}$ ), 5 (NIR - Infravermelho próximo 0,85-0,88 $\mu \mathrm{m}$ ) e 6 (SWIRInfravermelho de ondas curtas 1,57-1,65 $\mu \mathrm{m}$ ) do sensor OLI/Landsat8 (Figura 2). Posteriormente, realizouse a composição colorida 5R6G4B (por meio de um modelo criado para processar lotes de dados no software QGis 2.18). Durante esta etapa, foi possível concluir que a composição colorida escolhida apresentou melhor identificação da cana-de-açúcar em diferentes estádios fenológicos.

Figura 2 - Mosaico e composição colorida (5R6G4B) das imagens OLI/Landsat-8.

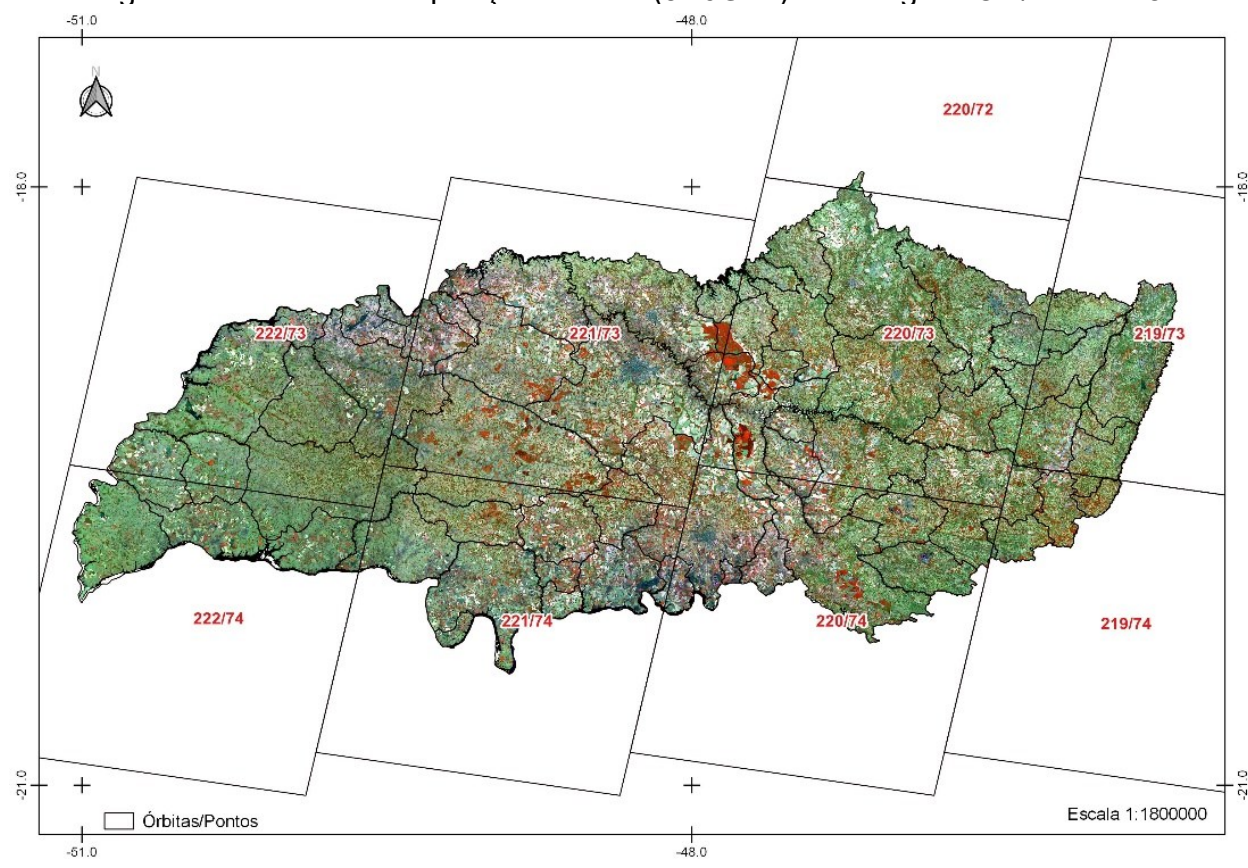

Fonte - da Autora, 2020.

A projeção cartográfica do conjunto de imagens do sensor OLI/Landsat8 adquiridas da USGS (United States Geological Survey), foi convertida de UTM (Universal Transversa Mercator), zonas 22 e 23 e Datum WGS84 (World Geodetic System 1984), para a Projeção Cônica de Lambert, pois de acordo com Rangel (2003, p. 52), além de ser uma projeção conforme, é baseada num cone secante ao globo terrestre, produzindo dois paralelos padrões, que possibilitam a projeção de uma área maior com baixa deformação. 


\title{
Mapeamento da cana-de-açúcar
}

Os dados de NDVI obtidos pelo satélite PROBA-V não passaram por nenhuma técnica de filtragem. As imagens serviram para extração dos atributos e formação do modelo de conhecimento por classificação automática.

A classificação automática supervisionada das imagens foi feita utilizando o Random Forest (RF) disponibilizado pelo Google Earth Engine. Foram utilizados atributos fenológicos tais como: (1) início de ciclo; (2) final de ciclo; (3) tamanho de ciclo; (4) amplitude e (5) área abaixo da curva. Os atributos e amostras $($ Cana = 1 e Não Cana $=0)$ formaram o modelo de conhecimento e as regiões foram automaticamente classificadas pixel a pixel.

A classificação RF gerou uma imagem de probabilidade (0-100). Altos valores de probabilidade estão relacionados aos pixels que pertencem à classe cana, e o oposto se aplica a não cana. Foram criados 12 intervalos (probabilidade >95, >90, >85, >80, >75, > 70, > 65, >60, > 55, > 50, > 45 e > 40) para a seleção dos pixels de cana, que resultaram em 12 máscaras, empregadas para geração de mapas, que depois de analisados, possibilitaram a escolha daqueles que, cujos resultados, se aproximaram da estimativa oficial declarada pelo IBGE, ou seja, o intervalo $>75$.

\section{Identificação do sistema de manejo da colheita da cana-de-açúcar}

Para identificar o sistema de manejo da colheita da cana-de-açúcar, antes da classificação, foi realizada a extração dos atributos das imagens de satélite do mês de setembro de 2017, no software Spring5.5.3, a partir do emprego da técnica do Modelo Linear de Mistura Espectral (MLME), que foi descrito por Shimabukuro e Smith (1991); Lobell e Asner (2004); e citado por Aguiar (2010, p.3) como:

\begin{abstract}
Uma técnica de análise subpixel e parte do princípio que o valor, na escala de cinza, assumido pelo pixel é uma combinação linear da refletância, em um determinado comprimento de onda, de diferentes alvos. Assim, cada pixel contém informação sobre a proporção e a resposta espectral de cada componente dentro do elemento de resolução espacial do sensor.
\end{abstract}

Para executar o MLME é necessário selecionar pixels puros (endmembers) dos alvos conforme o interesse, neste caso, a cana-de-açúcar mecanizada (cana mecanizada), queimada (cana queimada) e a bisada (cana bisada), para em seguida gerar as imagens fração. A Figura 3 exemplifica as imagens correspondentes a cada alvo determinado. No método, há redução da mistura do pixel e o realce dos alvos de interesse (SHIMABUKURO E PONZONI, 2017).

Figura 3 - Resposta espectral dos componentes: cana-de-açúcar mecanizada (a), cana-de-açúcar bisada (b) e canade-açúcar queimada (c).

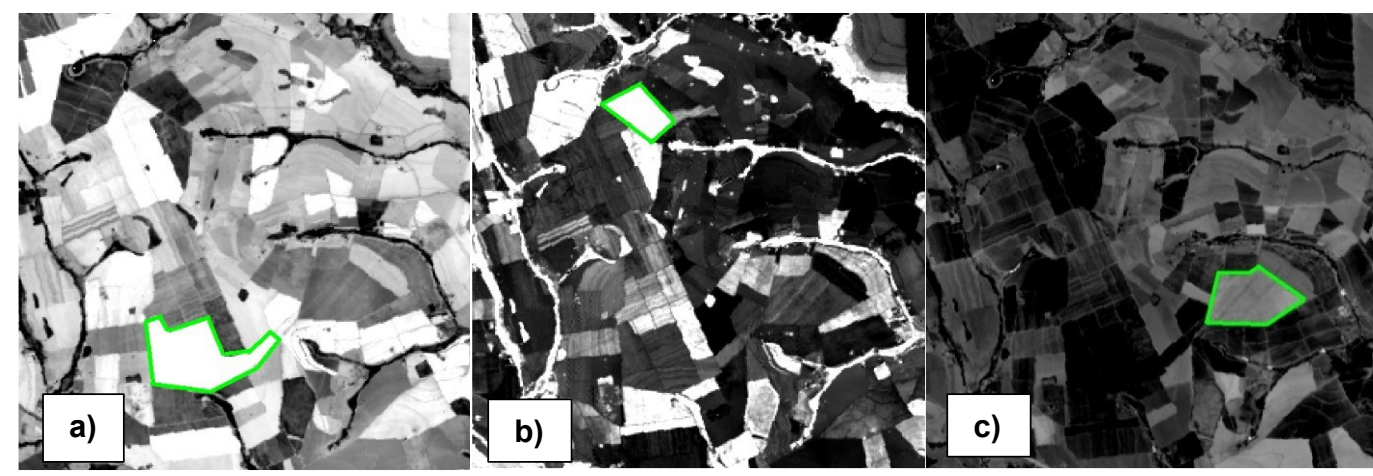

Fonte - da Autora, 2019.

Vale ressaltar que as imagens em reflectância de superfície que compuseram o mosaico são dadas em 16 bits, no entanto, quando processadas no software Spring 5.5.3, as imagens fração derivadas da técnica do MLME são transformadas automaticamente em 8 bits. Nessa transformação, os valores numéricos dos pixels são modificados, por isso, a utilização das imagens fração deu-se apenas no processo de segmentação, que será descrito em seguida.

A classificação automática foi realizada no software InterIMAGE após a inserção do mosaico (8 bits) do mês de setembro e das imagens fração do MLME (8 bits) visando a segmentação, que fornece a base para a análise orientada a objeto, por meio das regiões que contenham semelhanças espectrais. Para isso, o algoritmo multiresolution agrupa os pixels em regiões homogêneas. Baatz e Schäpe (2000) mencionaram

$\begin{array}{llllll}\text { Caminhos de Geografia } & \text { Uberlândia-MG } & \text { v. 21, n. } 77 & \text { Out/2020 } & \text { p. 263-282 } & \text { Página } 267\end{array}$


que o algoritmo multiresolution possui dois componentes: "a) decision Heuristics to determine the image objects that will merge at each step, b) definition of a homogeneity of image objects to compute the degree of fitting for a pair of image objects". Os parâmetros adotados foram: o Fator escala (Fe), no qual determina a diferença máxima permitida para os objetos da imagem (30), a Compacidade (Cp), valor 0,5 usado para otimizar objetos compactos, e a Forma (Fm), baseada no desvio de uma forma compacta (ou suave) sendo 0,3 o valor atribuído (SCHULTZ et al. 2016; MATSUOKA e HAERTEL, 2007; TRIMBLE GEOSPATIAL, 2014).

Em seguida, foi realizada a inserção do mosaico (16 bits) por meio da Object-based Image Analysis (OBIA), em que segmentos de amostras foram coletados para o treinamento das classes definidas como cana-deaçúcar mecanizada, queimada, bisada e/ou outros usos da terra. Costa el al. (2014) esclareceram que se considera cana bisada, aquela que permanece dois verões no campo, os autores apontaram que para algumas usinas tal matéria-prima é considerada apta ao processamento no início de safra devido ao seu alto teor de sacarose e de fibra.

A Figura 4 demonstra a chave de interpretação empregada na identificação dos diferentes sistemas de manejo da colheita da cana-de-açúcar, que no caso da cana colhida mecanicamente apresenta forma geométrica, textura lisa e, variadas tonalidades de vermelho (para a cana crua) ou branca (representando a ausência de vegetação e a alta reflectância devido a presença da palhada após a colheita com a máquina), conforme Figura $4 a$. Verifica-se na Figura $4 b$, que a cana queimada apresenta forma geométrica, textura lisa, e variação das cores vermelha (cana crua) a azul (após ser queimada). Já a cana bisada (Figura 4c), possui os mesmos padrões de textura e forma das demais, mantendo a cor vermelha durante todos os meses analisados (de abril a outubro).

Figura 4 - Chave de interpretação da cana-de-açúcar.

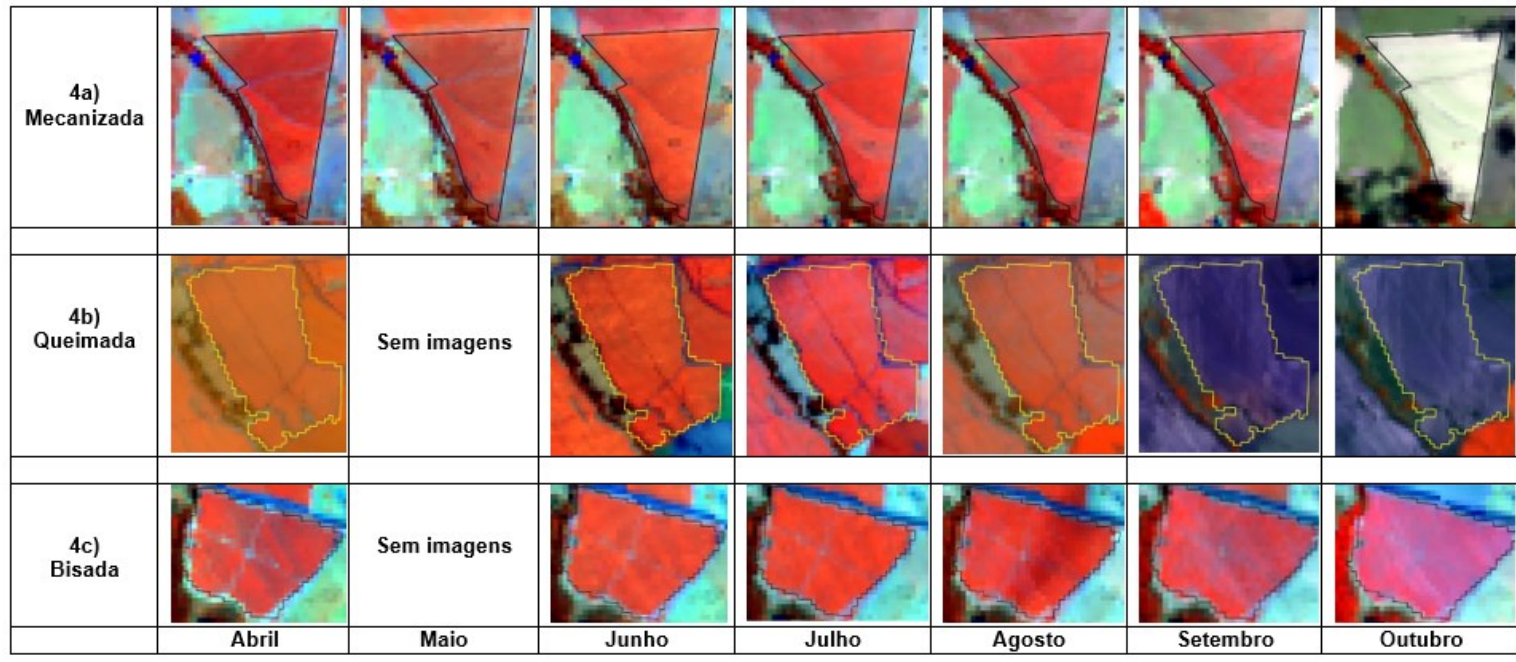

Fonte - da Autora, 2020.

Posteriormente à coleta das amostras, no InterIMAGE, foi gerada a classificação automática utilizando o algoritmo de classificação C4.5, que foi descrito por Debastiani et al. (2013, p.1) como um "classificador estatístico baseado no conceito de entropia, onde cada nó, o algoritmo determina qual padrão realiza uma melhor separação entre classes, gerando uma árvore univariada (onde cada regra é baseada em somente um atributo".

Com base no resultado obtido na classificação $C 4.5$, as áreas classificadas como cana-de-açúcar juntaramse às informações da máscara do Proba-V de $75 \%$, e por meio da ferramenta de localização foram selecionadas as áreas com maior probabilidade de serem cana, e, posteriormente, as imagens multitemporais dos outros meses serviram para reclassificar as áreas, a fim de melhorar o resultado final obtido.

Para a validação do mapeamento, foi utilizado um conjunto de 1040 pontos sorteados aleatoriamente na Mesorregião por meio da ferramenta "Pontos aleatórios na extensão" do software QGIS 3.2 e em seguida, foi atribuída, a cada um dos pontos, uma classe correspondente à classificação C4.5, auxiliada pela interpretação visual das imagens multitemporais. Os resultados da validação (Tabela 1) demonstraram que o Índice Kappa e a Exatidão Global foram 0,81 e 0,96, respectivamente, sendo considerado "muito bom" (CONGALTON, 1975). 
Tabela 1 - Matriz de confusão, Índice Kappa e Exatidão Global com base em 1040 pontos de referência.

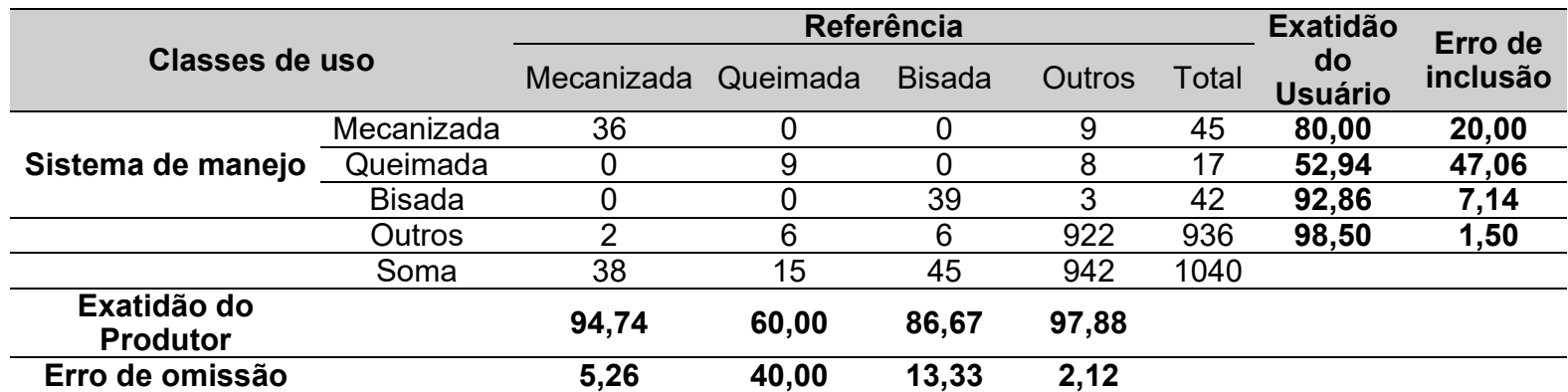

Índice Kappa = 0,81 e Exatidão Global = 0,96. Fonte - da Autora, 2020.

\section{RESULTADOS E DISCUSSÃO}

\section{Panorama da área cultivada com cana-de-açúcar no TMAP}

Os resultados da pesquisa demonstraram que no ano 2015, o TMAP totalizou 718.065 ha (Tabela 2), subdivididos em cana mecanizada (516.251 ha), cana queimada (51.317 ha) e cana bisada (150.497 ha).

Tabela 2 - Expansão da cana-de-açúcar, sistemas de manejo e cana bisada no TMAP (2015 e 2017).

\begin{tabular}{l|cc|cc|c}
\hline & \multicolumn{2}{|c|}{2015} & \multicolumn{2}{c|}{$\mathbf{2 0 1 7}$} & $\Delta$ \\
\hline Sistema de Manejo & (ha) & $\%$ & (ha) & \% & (ha) \\
\hline Mecanizada & 516.251 & 71,9 & 321.438 & 49,2 & -194.813 \\
\hline Queimada & 51.317 & 7,1 & 85.548 & 13,1 & 34.231 \\
\hline Bisada & 150.497 & 21 & 246.754 & 37,7 & 96.257 \\
\hline Total & $\mathbf{7 1 8 . 0 6 5}$ & $\mathbf{1 0 0}$ & $\mathbf{6 5 3 . 7 4 0}$ & $\mathbf{1 0 0}$ & $-\mathbf{6 4 . 3 2 5}$ \\
\hline \multicolumn{7}{r}{ Fonte - da Autora, 2020. }
\end{tabular}

Quando se analisam os dados de 2017, verifica-se uma redução de 64.325 ha da área total ocupada pela cana naquele ano (653.740 ha). Embora essa diminuição não tenha ultrapassado 10 pontos percentuais, constatou-se queda de 194.813 (22,7 pontos percentuais) na área plantada com cana mecanizada, enquanto houve aumento de 34.231 ha de cana queimada (13,1 pontos percentuais) e 96.257 ha da bisada (37,7 pontos percentuais), conforme verifica-se no Figura 5.

Figura 5 - Expansão da cana-de-açúcar e sistemas de manejo e cana bisada no TMAP (2015 e 2017).

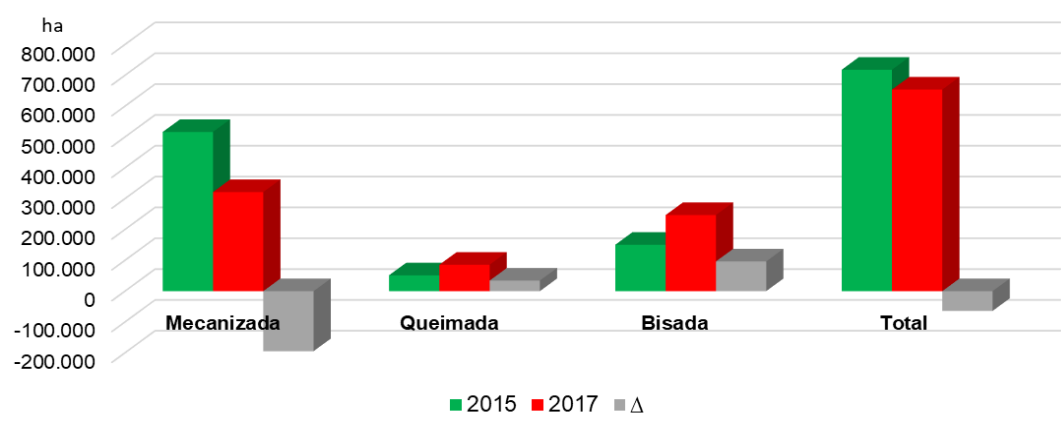

Fonte - da Autora, 2020.

O decréscimo observado em 2017, quando comparado a 2015, pode ser resultado do prolongado período de estiagem que ocorreu de maio a outubro de 2017, da ocorrência de queimadas e incêndios nas áreas colhidas e com cana-de-açúcar em desenvolvimento, que afetaram negativamente as soqueiras e as canasplantas (CONAB, 2017). Tais fatores podem justificar o aumento de 16,7 pontos percentuais na área ocupada com a cana bisada, 6 pontos percentuais na área queimada e a redução de cerca de 22,7 pontos percentuais na cana mecanizada. Consequentemente, os dados do mapeamento permitiram verificar que em 2015 a cana-de-açúcar representava 7,9\% do total da área do TMAP, ao passo que em 2017 essa cifra atingiu os $7,2 \%$. 
Além do exposto, a redução da área colhida no período analisado (que compreende a safra 2017/2018) pode estar associada aos seguintes fatores apontados pela $\operatorname{CONAB}(2017$, p. 48): "a prática da rotação de cultura; a não renovação de contratos de arrendamento em área de terceiros e, ainda, à paralisação de uma unidade produtiva".

Os resultados apresentados nas Tabelas 3 e 4 elucidam que das microrregiões que compõem o TMAP, as maiores produtoras de cana-de-açúcar são Uberaba e Frutal, tanto em 2015, quanto em 2017, o que pode estar associado à fronteira com o estado de São Paulo (maior produtor do país).

Proporcionalmente ao total ocupado pela cana no TMAP, independentemente do sistema de manejo, a microrregião de Frutal chegou a ocupar $34,3 \%$ do total da área em 2015, tendo decrescido para $29,5 \%$ em 2017. O mesmo foi verificado com a microrregião de Uberaba, que ocupava $31,5 \%$ do total em 2015 , e chegou a 31,1\% em 2017. Fenômeno contrário foi observado nas microrregiões de Araxá (de 8,9\% para $10,6 \%$ ), Ituiutaba (de $12,6 \%$ para $14,1 \%$ ) e Uberlândia (12,6\% para $14,7 \%$ ), visto que houve crescimento quando se considera o período de 2015 a 2017.

Tabela 3 - Área ocupada (ha e \%) pela cana-de-açúcar nas microrregiões do TMAP (2015).

\begin{tabular}{|c|c|c|c|c|c|c|c|}
\hline \multirow{3}{*}{ Microrregião } & \multicolumn{6}{|c|}{ Sistema de Manejo } & \multirow{3}{*}{$\begin{array}{c}\text { Total } \\
\text { ha }\end{array}$} \\
\hline & \multicolumn{2}{|c|}{ Mecanizada } & \multicolumn{2}{|c|}{ Queimada } & \multicolumn{2}{|c|}{ Bisada } & \\
\hline & ha & $\%$ & ha & $\%$ & ha & $\%$ & \\
\hline Araxá & 53.666 & 84,3 & 1.503 & 2,4 & 8.438 & 13,3 & 63.607 \\
\hline Frutal & 174.360 & 70,7 & 14.685 & 6,0 & 57.423 & 23,3 & 246.468 \\
\hline Ituiutaba & 59.753 & 66,2 & 3.656 & 4,1 & 26.813 & 29,7 & 90.222 \\
\hline Patos de Minas & 0 & 0 & 0 & 0 & 415 & 100 & 415 \\
\hline Patrocínio & 131 & 15,8 & 0 & 0 & 700 & 84,2 & 831 \\
\hline Uberlândia & 63.315 & 70,1 & 7.705 & 8,5 & 19.350 & 21,4 & 90.370 \\
\hline Uberaba & 165.026 & 73,0 & 23.768 & 10,5 & 37.358 & 16,5 & 226.152 \\
\hline Total & 516.251 & 71,9 & 51.317 & 7,1 & 150.497 & 21 & 718.065 \\
\hline
\end{tabular}

Org. - da Autora, 2020.

Tabela 4 - Área ocupada (ha e \%) pela cana-de-açúcar nas microrregiões do TMAP (2017).

\begin{tabular}{|c|c|c|c|c|c|c|c|}
\hline \multirow{3}{*}{ Microrregião } & \multicolumn{6}{|c|}{ Sistema de Manejo } & \multirow{3}{*}{$\begin{array}{c}\text { Total } \\
\text { ha }\end{array}$} \\
\hline & \multicolumn{2}{|c|}{ Mecanizada } & \multicolumn{2}{|c|}{ Queimada } & \multicolumn{2}{|c|}{ Bisada } & \\
\hline & ha & $\%$ & ha & $\%$ & ha & $\%$ & \\
\hline Araxá & 42.477 & 61,5 & 4.655 & 6,7 & 21.943 & 31,8 & 69.074 \\
\hline Frutal & 90.431 & 46,8 & 25.661 & 13,3 & 76.947 & 39,9 & 193.039 \\
\hline Ituiutaba & 50.234 & 55,0 & 15.244 & 16,7 & 25.918 & 28,4 & 91.396 \\
\hline Patos de Minas & 0 & 0 & 0 & 0 & 0 & 0 & 0 \\
\hline Patrocínio & 115 & 100 & 0 & 0 & 0 & 0 & 115 \\
\hline Uberlândia & 52.489 & 54,8 & 8.055 & 8,4 & 35.155 & 36,7 & 95.699 \\
\hline Uberaba & 85.693 & 41,9 & 31.933 & 15,6 & 86.791 & 42,5 & 204.417 \\
\hline Total & 321.438 & 49,2 & 85.548 & 13,1 & 246.754 & 37,7 & 653.740 \\
\hline
\end{tabular}

Em razão do objetivo do trabalho, as autoras optaram por não discutir os dados relativos à cana bisada nas microrregiões do TMAP, portanto, as análises que se seguem consideraram somente o sistema de manejo da cana mecanizada e da queimada.

\section{Monitoramento do sistema de manejo do corte da cana mecanizada e com emprego do fogo nas microrregiões do TMAP}

A Figura 6 espacializa os dados detalhados nas Tabela 5 acerca do sistema de manejo da colheita da canade-açúcar nas microrregiões do TMAP nos anos de 2015 e 2017, suas análises comprovam que o corte mecanizado da cana ( $91,0 \%$ em 2015 , e $79,0 \%$ em 2017$)$ é superior ao emprego do fogo $(9,0 \%$ em 2015 , e $21,0 \%$ em 2017). 
Figura 6 - Mapeamento da colheita da cana-de-açúcar no TMAP (2015-2017)

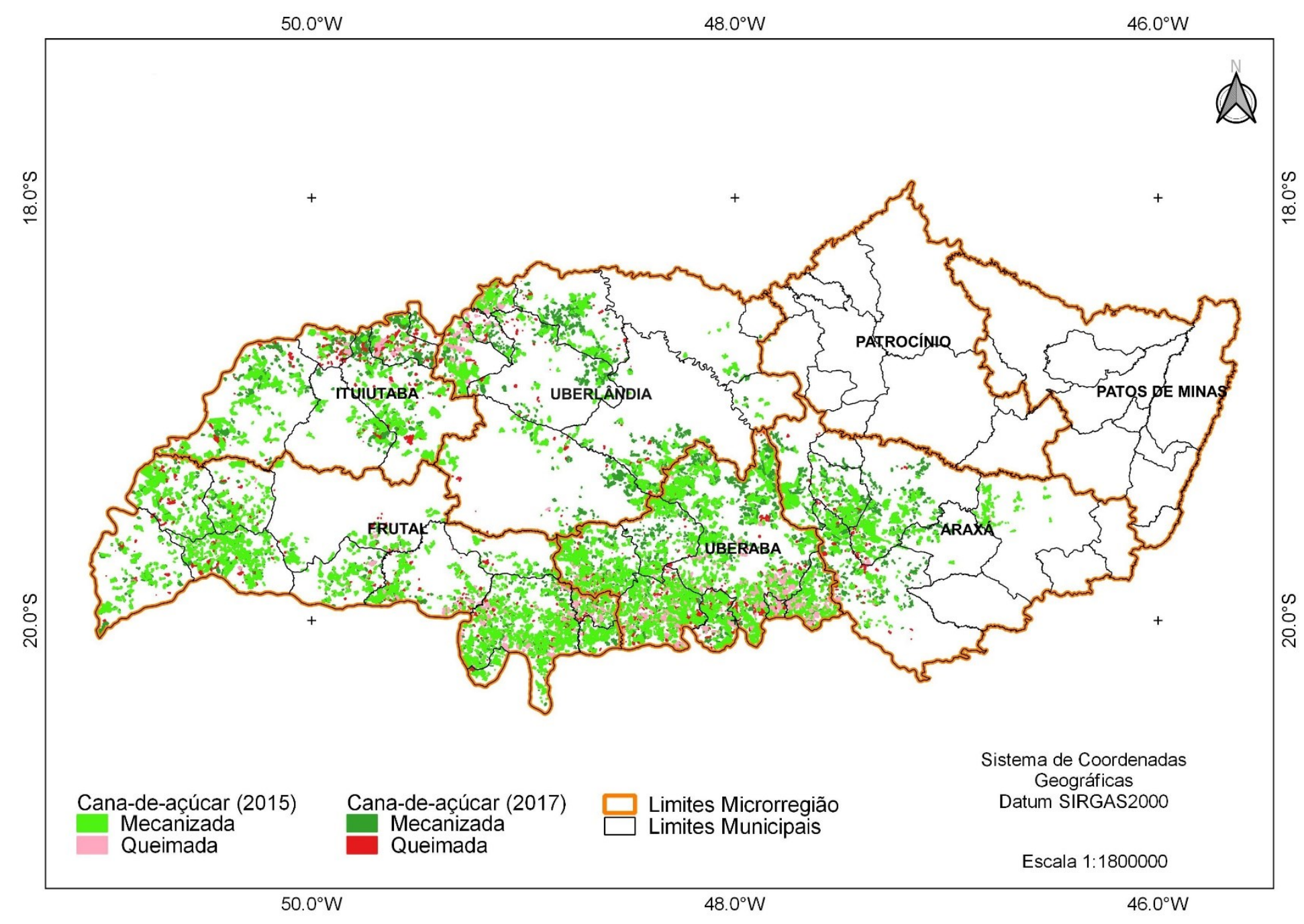

Fonte - da Autora, 2020. 
Surpreendentemente, verificou-se que em todas as microrregiões houve redução da área mecanizada e incremento das queimadas (Tabela 5), com destaque para Frutal, que perdeu 83.929 ha de colheita mecanizada, ao mesmo tempo em que ocorreu aumento de 10.976 ha com uso do fogo com relação ao período anteriormente analisado, ficando atrás apenas de Ituiutaba, cujo saldo foram 11.588 ha queimados a mais. Em termos absolutos, a microrregião de Uberaba é a que possui a maior extensão de área queimada, ao todo foram queimados 23.768 ha, em 2015, e 31.933 ha, em 2017, o que representou um incremento de 8.165 ha.

Tabela 5 - Expansão da cana-de-açúcar por sistemas de manejo nas microrregiões do TMAP (2015 e 2017).

\begin{tabular}{|c|c|c|c|c|c|c|c|c|c|c|}
\hline \multirow{3}{*}{ Microrregiões } & \multicolumn{4}{|c|}{2015} & \multicolumn{4}{|c|}{2017} & \multirow{2}{*}{\multicolumn{2}{|c|}{$\begin{array}{c}\Delta \\
\text { Queimada }\end{array}$}} \\
\hline & \multicolumn{2}{|c|}{ Mecanizada } & \multicolumn{2}{|c|}{ Queimada } & \multicolumn{2}{|c|}{ Mecanizada } & \multicolumn{2}{|c|}{ Queimada } & & \\
\hline & ha & $\%$ & ha & $\%$ & ha & $\%$ & ha & $\%$ & ha & ha \\
\hline Araxá & 53.666 & 97,3 & 1.503 & 2,7 & 42.477 & 90,1 & 4.655 & 9,9 & -11.189 & 3.152 \\
\hline Frutal & 174.360 & 92,2 & 14.685 & 7,8 & 90.431 & 77,9 & 25.661 & 22,1 & -83.929 & 10.976 \\
\hline Ituiutaba & 59.753 & 94,2 & 3.656 & 5,8 & 50.234 & 76,7 & 15.244 & 23,3 & -9.519 & 11.588 \\
\hline Patos de Minas & 0 & 0,0 & 0 & 0,0 & 0 & 0,0 & 0 & 0,0 & 0 & 0 \\
\hline Patrocínio & 131 & 0,0 & 0 & 0,0 & 115 & 99,3 & 1 & 0,7 & -16 & 1 \\
\hline Uberlândia & 63.315 & 89,2 & 7.705 & 10,8 & 52.489 & 86,7 & 8.055 & 13,3 & -10.826 & 350 \\
\hline Uberaba & 165.026 & 87,4 & 23.768 & 12,6 & 85.693 & 72,9 & 31.933 & 27,1 & -79.333 & 8.165 \\
\hline TOTAL & 516.251 & 91,0 & 51.317 & 9,0 & 321.438 & 79,0 & 85.550 & 21,0 & -194.813 & 34.233 \\
\hline
\end{tabular}

As microrregiões de Frutal e Uberaba possuem as maiores áreas colhidas, seguidas de Uberlândia, Ituiutaba e Araxá. Por outro lado, as de Patos de Minas e Patrocínio não apresentaram áreas plantadas ou estimativas de produção relevantes (Figura 7), sendo predominante o cultivo de soja, milho e café (conforme dados do IBGE, 2018). Nascimento (2014) explanou sobre o reconhecimento nacional de Patrocínio pela produção e exportação de cafés especiais, utilizando modernas técnicas agrícolas adaptadas ao solo do bioma Cerrado.

Figura 7 - Área colhida (ha) de acordo com o sistema de manejo da cana-de-açúcar nas microrregiões do TMAP (2015-2017).

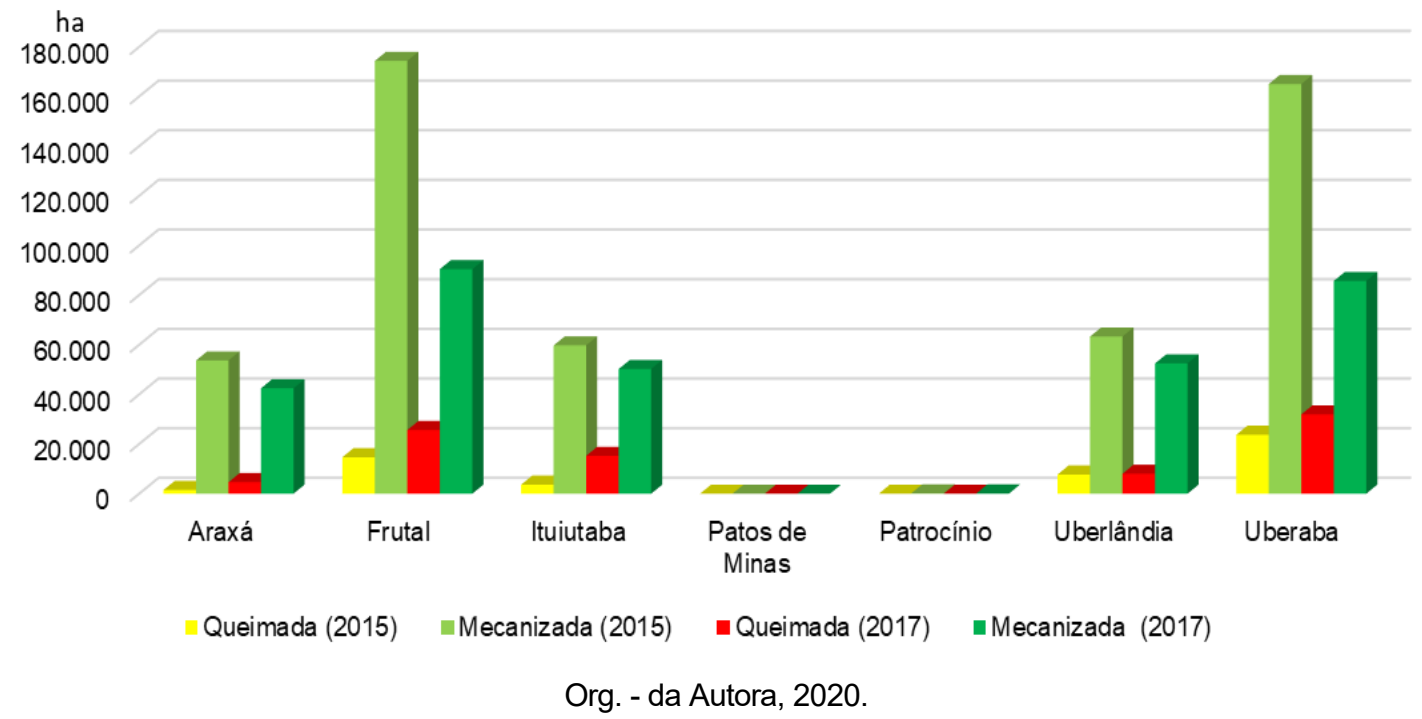


Ao analisar os resultados do mapeamento da microrregião de Frutal (Figura 8 e 9, Tabela 6), verifica-se que os municípios de Frutal, Itapagipe, Iturama e Limeira do Oeste são os que possuem maior área cultivada com cana, enquanto Comendador Gomes e Fronteira têm a menor produção, estes últimos não apresentaram áreas queimadas no ano 2015. De maneira geral, verificou-se o aumento das áreas queimadas em todos os municípios da microrregião de Frutal no ano 2017 (Tabela 6), representando um crescimento de 75\% com relação ao ano 2015.

Figura 8 - Sistema de manejo da cana-de-açúcar na microrregião de Frutal (2015-2017).

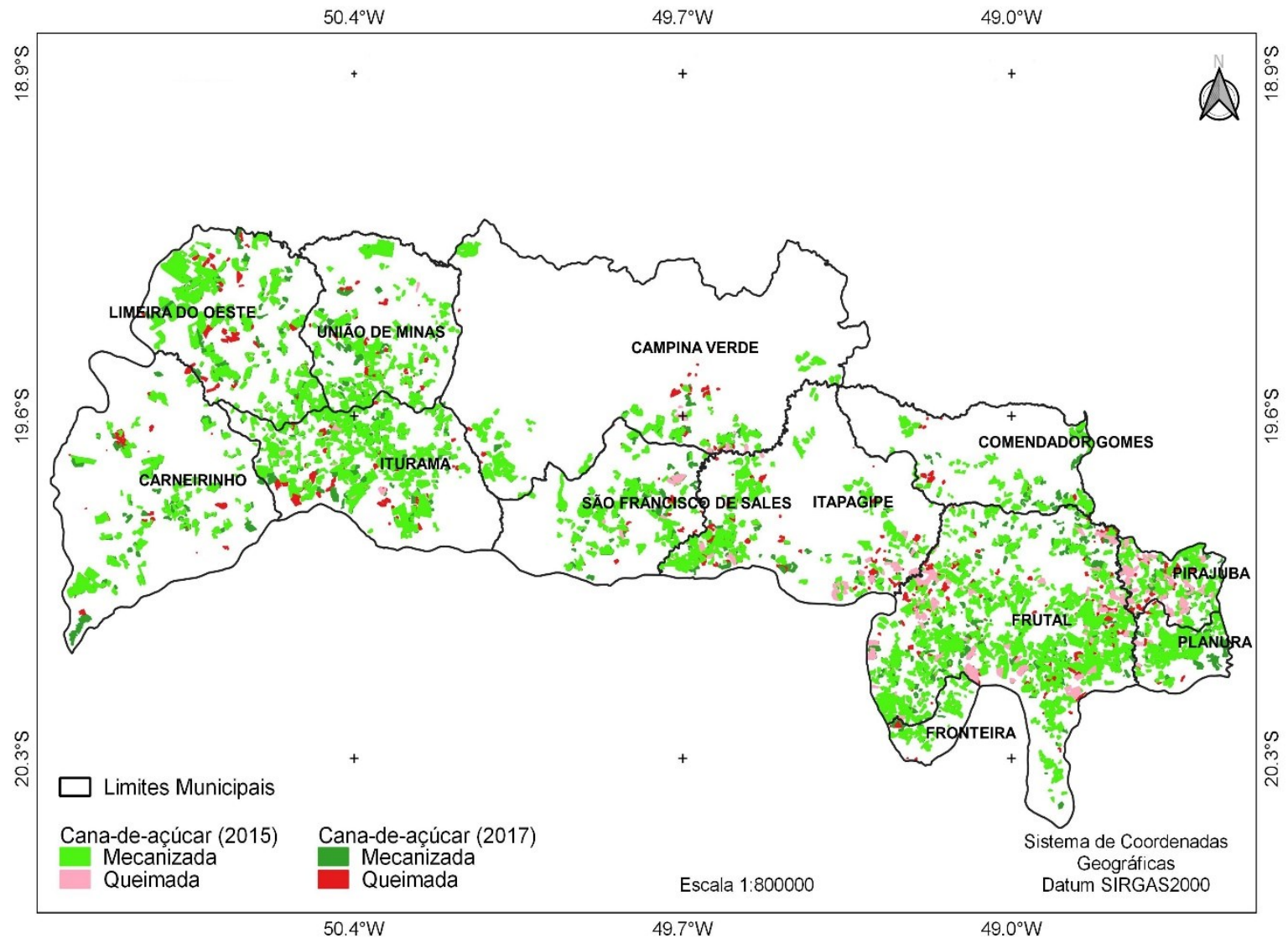

Fonte - da Autora, 2020.

Figura 9 - Área colhida (ha) de acordo com o sistema de manejo da cana-de-açúcar na microrregião de Frutal (2015-2017).

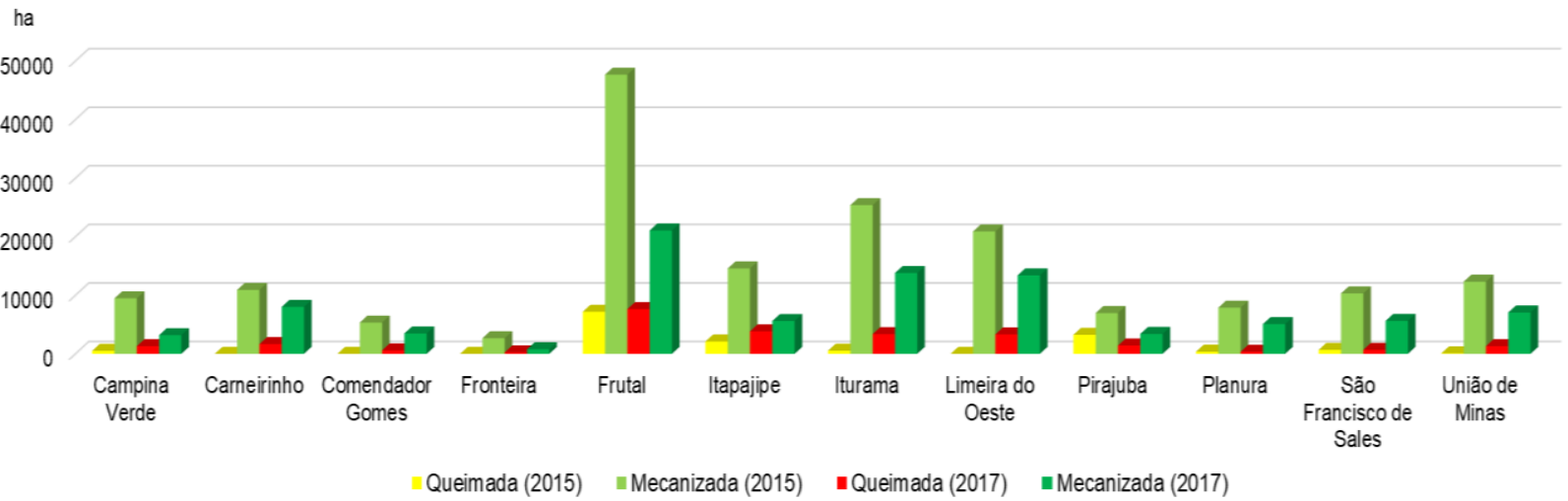

Org. - da Autora, 2020.

\begin{tabular}{|c|c|c|c|}
\hline Caminhos de Geografia & Uberlândia-MG & v. 21, n. 77 & Out/2020 \\
\hline
\end{tabular}


Tabela 6 - Sistema de manejo da cana-de-açúcar (ha) na microrregião de Frutal (2015-2017).

\begin{tabular}{|c|c|c|c|c|c|c|c|c|c|c|}
\hline \multirow{3}{*}{ Municípios } & \multicolumn{5}{|c|}{2015} & \multicolumn{5}{|c|}{2017} \\
\hline & \multicolumn{2}{|c|}{ Queimada } & \multicolumn{2}{|c|}{ Mecanizada } & \multirow{2}{*}{$\begin{array}{c}\text { Total } \\
\text { ha }\end{array}$} & \multicolumn{2}{|c|}{ Queimada } & \multicolumn{2}{|c|}{ Mecanizada } & \multirow{2}{*}{$\begin{array}{c}\text { Total } \\
\text { ha }\end{array}$} \\
\hline & ha & $\%$ & ha & ha & & ha & $\%$ & ha & $\%$ & \\
\hline $\begin{array}{l}\text { Campina } \\
\text { Verde }\end{array}$ & 505 & 5,1 & 9.474 & 94,9 & 9.979 & 1.301 & 29,0 & 3.186 & 71,0 & 4.487 \\
\hline Carneirinho & 0 & 0,0 & 10.910 & 10 & 10.910 & 1.660 & 17,2 & 8.008 & 82,8 & 9.668 \\
\hline $\begin{array}{c}\text { Comendador } \\
\text { Gomes }\end{array}$ & 0 & 0,0 & 5.326 & 100 & 5.326 & 574 & 14,2 & 3.476 & 85,8 & 4.050 \\
\hline Fronteira & 0 & 0,0 & 2.666 & 100 & 2.666 & 245 & 23,9 & 778 & 76,1 & 1.023 \\
\hline Frutal & 7.176 & 13,1 & 47.670 & 86,9 & 54.846 & 7.636 & 26,6 & 21.061 & 73,4 & 28.697 \\
\hline Itapajipe & 2.104 & 12,6 & 14.576 & 87,4 & 16.680 & 3.831 & 40,7 & 5.589 & 59,3 & 9.420 \\
\hline Iturama & 534 & 2,1 & 25.381 & 97,9 & 25.915 & 3.366 & 19,6 & 13.800 & 80,4 & 17.166 \\
\hline $\begin{array}{l}\text { Limeira do } \\
\text { Oeste }\end{array}$ & 0 & 0,0 & 20.891 & 100 & 20.891 & 3.310 & 19,8 & 13.392 & 80,2 & 16.702 \\
\hline Pirajuba & 3.251 & 31,8 & 6.960 & 68,2 & 10.211 & 1.415 & 29,4 & 3.390 & 70,6 & 4.805 \\
\hline Planura & 366 & 4,4 & 7.875 & 95,6 & 8.241 & 355 & 6,5 & 5.077 & 93,5 & 5.432 \\
\hline $\begin{array}{c}\text { São } \\
\text { Francisco de } \\
\text { Sales }\end{array}$ & 670 & 6,1 & 10.314 & 93,9 & 10.984 & 663 & 10,5 & 5.620 & 89,5 & 6.283 \\
\hline $\begin{array}{c}\text { União de } \\
\text { Minas }\end{array}$ & 79 & 0,6 & 12.317 & 99,4 & 12.396 & 1.305 & 15,6 & 7.054 & 84,4 & 8.359 \\
\hline Total & 14.685 & 7,8 & 174.360 & 92,2 & 189.045 & 25.661 & 22,1 & 90.431 & 77,9 & 116.092 \\
\hline
\end{tabular}

Org. - da Autora, 2020.

A microrregião de Uberaba detém a maior área cultivada com cana-de-açúcar do estado, sendo os municípios de Uberaba, Conceição das Alagoas e Campo Florido os maiores produtores (Figura 10).

Figura 10 - Sistema de manejo da cana-de-açúcar na microrregião de Uberaba (2015-2017).

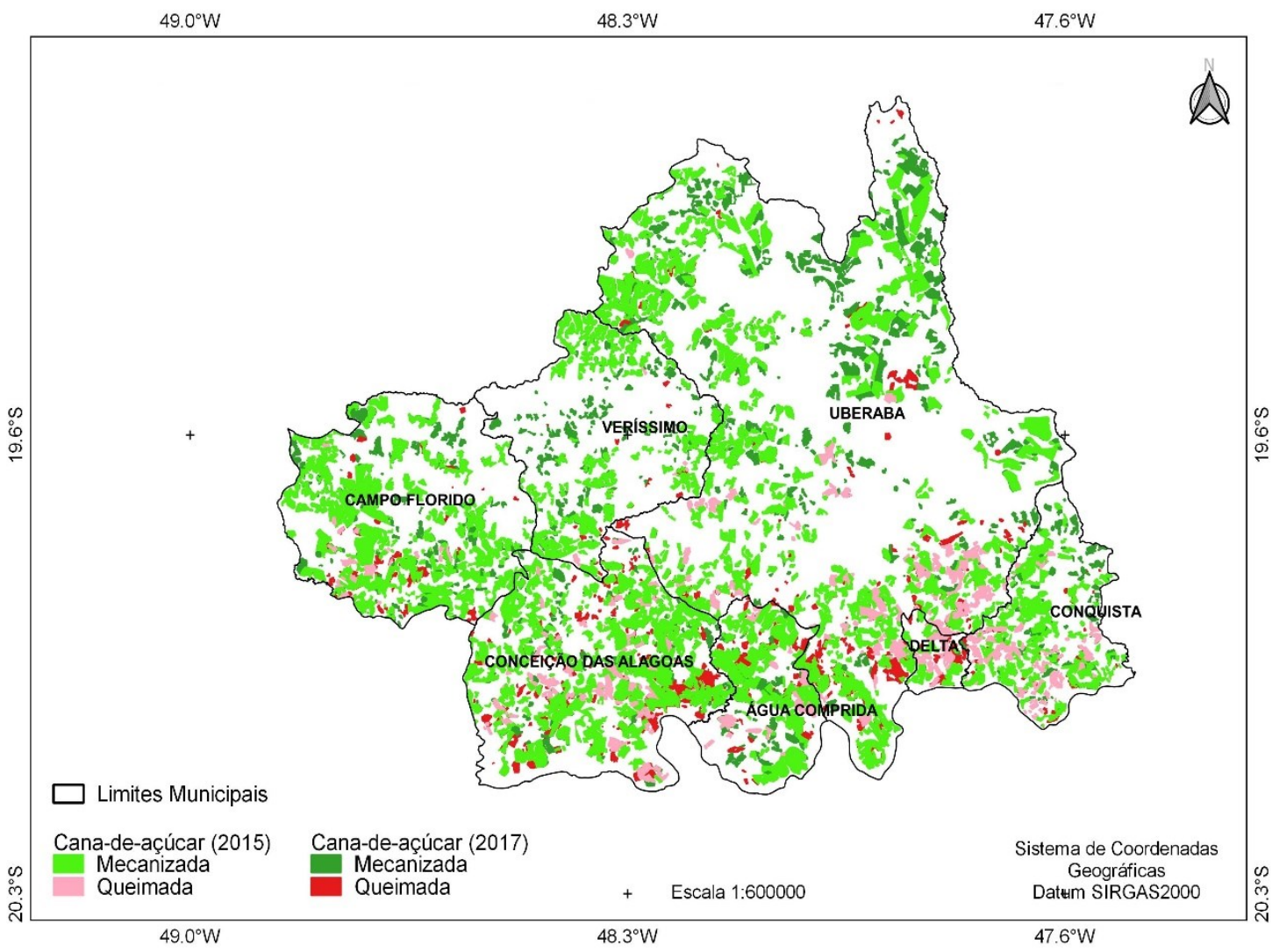

Fonte. - da Autora, 2020.

$\begin{array}{lllll}\text { Caminhos de Geografia } & \text { Uberlândia-MG } & \text { v. 21, n. } 77 & \text { Out/2020 } & \text { p. 263-282 }\end{array}$


Em 2015, os municípios que apresentaram maiores áreas colhidas com o emprego do fogo foram nos municípios de Frutal, Pirajuba e Itapajipe, respectivamente. Enquanto, em 2017, foram Frutal, Itapajipe e Iturama. No total, 14.685 ha foram colhidos empregando o fogo em 2015, correspondendo a 7,8\% da área total colhida, enquanto, em 2017, houve um aumento de 14,3 pontos percentuais, nessa prática, chegando a $22,1 \%$. Ao contrário do observado nas áreas com a colheita mecanizada, na qual houve queda de 14,3 pontos quando comparado a 2015.

A Tabela 7 e Figura 11 apontam que em 2015, a área referente a colheita com o uso do fogo foi de 23.768 ha $(12,6 \%)$, ao passo que, em 2017 , houve um aumento de 14,5 pontos percentuais, ou seja, 8.165 ha, totalizando área de 31.933 ha $(27,1 \%)$. Em relação a cana-de açúcar colhida mecanizada, verificou-se uma redução de 79.333 ha, de 2015 para 2017, passando de 165.026 ha (87,4\%) para 85.693 ha (72,9\%).

Tabela 7 - Sistema de manejo da cana-de-açúcar (ha) na microrregião de Uberaba (2015-2017).

\begin{tabular}{|c|c|c|c|c|c|c|c|c|c|c|}
\hline \multirow{3}{*}{ Municípios } & \multicolumn{5}{|c|}{2015} & \multicolumn{5}{|c|}{2017} \\
\hline & \multicolumn{2}{|c|}{ Queimada } & \multicolumn{2}{|c|}{ Mecanizada } & \multirow{2}{*}{$\begin{array}{c}\text { Total } \\
\text { ha }\end{array}$} & \multicolumn{2}{|c|}{ Queimada } & \multicolumn{2}{|c|}{ Mecanizada } & \multirow{2}{*}{$\begin{array}{c}\text { Total } \\
\text { ha }\end{array}$} \\
\hline & ha & $\%$ & ha & $\%$ & & ha & $\%$ & ha & $\%$ & \\
\hline $\begin{array}{c}\text { Água } \\
\text { Comprida }\end{array}$ & 2.030 & 14,1 & 12.335 & 85,9 & 14.365 & 3.256 & 34,3 & 6.225 & 65,7 & 9.481 \\
\hline $\begin{array}{l}\text { Campo } \\
\text { Florido }\end{array}$ & 1.333 & 4,6 & 27.925 & 95,4 & 29.258 & 2.700 & 17,2 & 13.000 & 82,8 & 15.700 \\
\hline $\begin{array}{c}\text { Conceição } \\
\text { das Alagoas }\end{array}$ & 5.589 & 14,1 & 34.095 & 85,9 & 39.684 & 11.685 & 51,7 & 10.909 & 48,3 & 22.594 \\
\hline Conquista & 3.927 & 26,3 & 10.984 & 73,7 & 14.911 & 1.844 & 22,4 & 6.390 & 77,6 & 8.234 \\
\hline Delta & 1.429 & 44,0 & 1.822 & 56,0 & 3.251 & 1.042 & 74,0 & 367 & 26,0 & 1.409 \\
\hline Uberaba & 9.268 & 12,6 & 64.354 & 87,4 & 73.622 & 10.757 & 20,8 & 40.923 & 79,2 & 51.680 \\
\hline Veríssimo & 192 & 1,4 & 13.511 & 98,6 & 13.703 & 650 & 7,6 & 7.879 & 92,4 & 8.529 \\
\hline Total & 23.768 & 12,6 & 165.026 & 87,4 & 188.794 & 31.933 & 27,1 & 85.693 & 72,9 & 117.626 \\
\hline
\end{tabular}

Figura 11 - Área colhida (ha) de acordo com o sistema de manejo da cana-de-açúcar na microrregião de Uberaba (2015-2017).

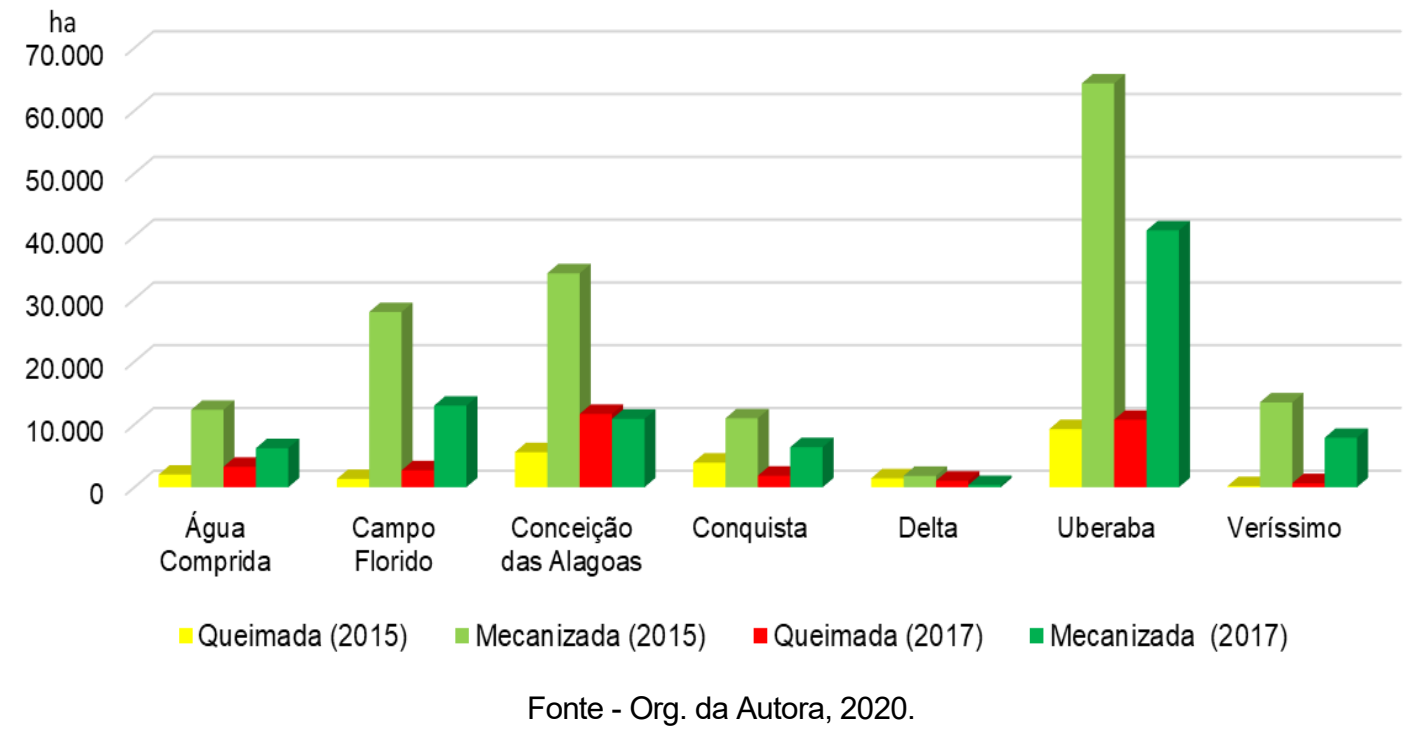

Além do exposto, a microrregião de Uberaba ocupa a primeira posição no emprego do fogo nos canaviais, de modo que 12,6\% (23.768 ha) da área total ocupada com cana foi queimada em 2015 e 27,1\% (31.933 ha) em 2017. No município de Conceição das Alagoas, mais de $50 \%$ da cana-de-açúcar produzida foi queimada no ano 2017, enquanto em 2015 a cifra alcançava 14,1\%. Apesar de insignificante a produção em Delta, mais de $70 \%$ da cana foi queimada em 2017.

\begin{tabular}{llllll}
\hline Caminhos de Geografia & Uberlândia-MG & v. 21, n. 77 & Out/2020 & p. 263-282 & Página 275
\end{tabular}


Observa-se que os municípios de Uberlândia, Tupaciguara e Centralina, situados na microrregião de Uberlândia, foram os únicos a apresentarem crescimento no cultivo de cana mecanizada em 2017 (Figura 12). Paralelamente a isso, a compilação dos resultados dos municípios para o total da referida microrregião, reflete o comportamento observado por todas demais quanto à redução, que neste caso foi de $15 \%$ (10.476 ha) do total de área cultivada de 2015 para 2017 (Tabela 8). Ao averiguar a área queimada, nota-se um aumento de 350 ha de 2015 para 2017.

Figura 12 - Sistema de manejo da cana-de-açúcar na microrregião de Uberlândia (2015-2017).

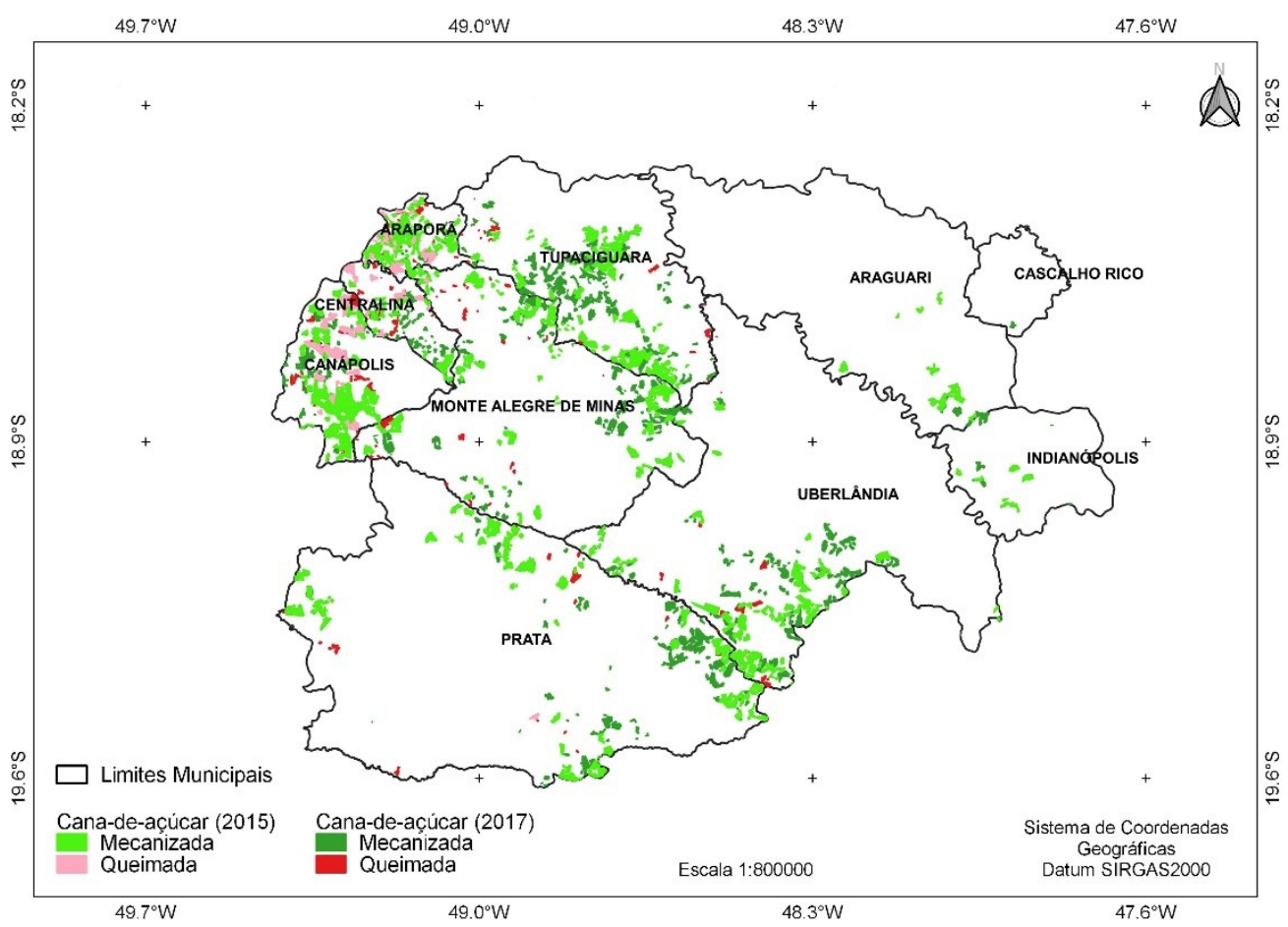

Fonte - da Autora, 2020.

Dos maiores produtores de cana detalhados na Tabela 8 (Uberlândia, Tupaciguara, Prata, Monte Alegre de Minas e Canápolis), o município de Tupaciguara apresentou apenas $0,9 \%$ do total de seus canaviais queimados em 2017.

Tabela 8 - Sistema de manejo da cana-de-açúcar (ha) na microrregião de Uberlândia (2015-2017).

\begin{tabular}{|c|c|c|c|c|c|c|c|c|c|c|}
\hline \multirow{3}{*}{ Municípios } & \multicolumn{5}{|c|}{2015} & \multicolumn{5}{|c|}{2017} \\
\hline & \multicolumn{2}{|c|}{ Queimada } & \multicolumn{2}{|c|}{ Mecanizada } & \multirow{2}{*}{$\begin{array}{l}\text { Total } \\
\text { ha }\end{array}$} & \multicolumn{2}{|c|}{ Queimada } & \multicolumn{2}{|c|}{ Mecanizada } & \multirow{2}{*}{$\begin{array}{c}\text { Total } \\
\text { ha }\end{array}$} \\
\hline & ha & $\%$ & ha & $\%$ & & ha & $\%$ & ha & $\%$ & \\
\hline Araguari & 0 & 0,0 & 1.875 & 100,0 & 1.875 & 0 & 0,0 & 1.045 & 100,0 & 1.045 \\
\hline Araporã & 2.002 & 24,9 & 6.043 & 75,1 & 8.045 & 1.617 & 45,7 & 1.919 & 54,3 & 3.536 \\
\hline Canápolis & 4.224 & 27,6 & 11.104 & 72,4 & 15.328 & 1.758 & 27,0 & 4.744 & 73,0 & 6.502 \\
\hline $\begin{array}{l}\text { Cascalho } \\
\text { Rico }\end{array}$ & 0 & 0,0 & 0 & 0,0 & 0 & 0 & 0,0 & 93 & 100,0 & 93 \\
\hline Centralina & 1.211 & 37,0 & 2.060 & 63,0 & 3.271 & 613 & 18,0 & 2.787 & 82,0 & 3.400 \\
\hline Indianópolis & 0 & 0,0 & 850 & 100,0 & 850 & 8 & 1,2 & 704 & 98,8 & 712 \\
\hline $\begin{array}{c}\text { Monte Alegre } \\
\text { de Minas }\end{array}$ & 95 & 1,0 & 9.682 & 99,0 & 9.777 & 978 & 10,0 & 8.765 & 90,0 & 9.743 \\
\hline Prata & 116 & 1,0 & 11.650 & 99,0 & 11.766 & 1.672 & 14,2 & 10.112 & 85,8 & 11.784 \\
\hline Tupaciguara & 0 & 0,0 & 10.338 & 100,0 & 10.338 & 687 & 0,9 & 10.436 & 99,1 & 11.123 \\
\hline Uberlândia & 57 & 0,6 & 9.713 & 99,4 & 9.770 & 724 & 17,8 & 11.884 & 82,2 & 12.608 \\
\hline Total & 7.705 & 10,8 & 63.315 & 89,2 & 71.020 & 8.055 & 13,3 & 52.489 & 86,7 & 60.544 \\
\hline
\end{tabular}


Figura 13 - Área colhida (ha) de acordo com o sistema de manejo da cana-de-açúcar na microrregião de Uberlândia (2015-2017).

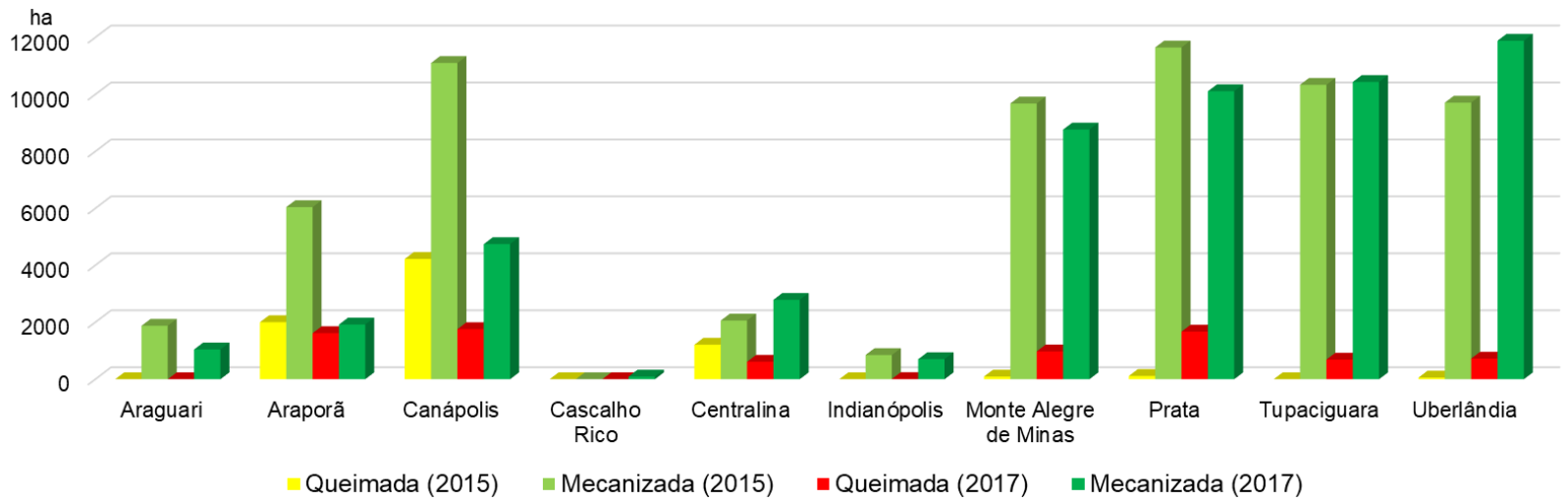

Org. - da Autora, 2020.

É possível inferir que a microrregião de Ituiutaba (Figura 14) foi responsável pelo segundo maior percentual de queimada da cana-de-açúcar, quando se considera a área ocupada $(23,0 \%)$ no ano 2017 . Calculou-se que o equivalente a $6,0 \%$ (3.653 ha) da cana cultivada na microrregião foi queimado em 2015. Chama a atenção o fato de que em 2017, todos os municípios desta microrregião passaram a utilizar o fogo na précolheita, com números variando de 11 a $34 \%$ por município, totalizando 15.244 ha $(23,0 \%)$. Para as áreas de colheita da cana-de-açúcar mecanizada, $100 \%$ das áreas dos municípios de Cachoeira Dourada, Gurinhatã e Santa Vitória destinadas a este fim, empregaram a colheita mecanizada em 2015, ao passo que em 2017, houve uma diminuição da porcentagem dos municípios, reflexo da redução na área colhida, que passou de 59.753 ha $(94,0 \%)$ para 50.234 ha $(77,0 \%)$.

Figura 14 - Sistema de manejo da cana-de-açúcar na microrregião de Ituiutaba (2015-2017).

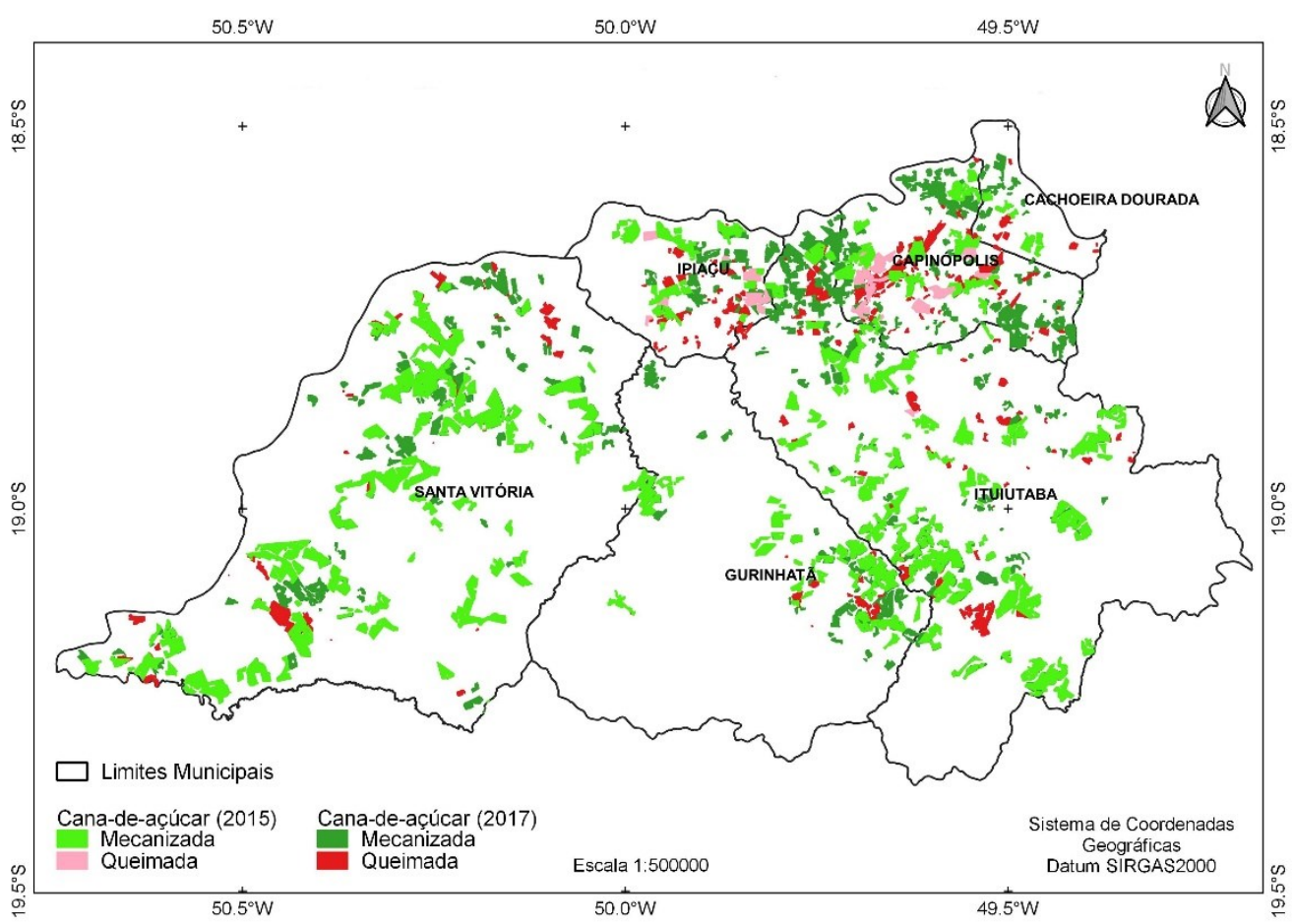

Org. - da Autora, 2020. 
Em 2015, Cachoeira Dourada, Gurinhatã e Santa Vitória não queimaram seus canaviais, todavia, em 2017, esse sistema de manejo foi empregado em $31 \%, 11,9 \%$ e $21,1 \%$ do total cultivado, respectivamente. Os municípios que tiveram as maiores áreas em ambos os anos foram Santa Vitória e Ituiutaba (Tabela 9).

Tabela 9 - Sistema de manejo da cana-de-açúcar (ha) na microrregião de Ituiutaba (2015-2017).

\begin{tabular}{|c|c|c|c|c|c|c|c|c|c|c|}
\hline \multirow{3}{*}{ Municípios } & \multicolumn{5}{|c|}{2015} & \multicolumn{5}{|c|}{2017} \\
\hline & \multicolumn{2}{|c|}{ Queimada } & \multicolumn{2}{|c|}{ Mecanizada } & \multirow{2}{*}{$\begin{array}{c}\text { Total } \\
\text { ha }\end{array}$} & \multicolumn{2}{|c|}{ Queimada } & \multicolumn{2}{|c|}{ Mecanizada } & \multirow{2}{*}{$\begin{array}{c}\text { Total } \\
\text { ha }\end{array}$} \\
\hline & ha & $\%$ & ha & $\%$ & & ha & $\%$ & ha & $\%$ & \\
\hline Cachoeira & 0 & 0,0 & 741 & 100,0 & & 401 & 31,0 & 892 & 69,0 & 1.293 \\
\hline Dourada & & & & & 741 & & & & & \\
\hline Capinópolis & 2.398 & 36,2 & 4.224 & 63,8 & 6.622 & 3.932 & 31,5 & 8.535 & 68,5 & 12.467 \\
\hline Gurinhatã & 0 & 0,0 & 5.720 & 100,0 & 5.720 & 774 & 11,9 & 5.755 & 88,1 & 6.529 \\
\hline Ipiaçu & 1.191 & 27,4 & 3.158 & 72,6 & 4.349 & 1.613 & 34,2 & 3.103 & 65,8 & 4.716 \\
\hline Ituiutaba & 67 & 0,3 & 19.634 & 99,7 & 19.701 & 4.144 & 21,0 & 15.569 & 79,0 & 19.713 \\
\hline Santa Vitória & 0 & 0,0 & 26.276 & 100,0 & 26.276 & 4.381 & 21,1 & 16.381 & 78,9 & 20.762 \\
\hline Total & 3.656 & 6,0 & 59.753 & 94,0 & 63.409 & 15.244 & 23,0 & 50.234 & 77,0 & 65.478 \\
\hline
\end{tabular}

Figura 15 - Área colhida (ha) de acordo com o sistema de manejo da cana-de-açúcar na microrregião de Ituiutaba (2015-2017)

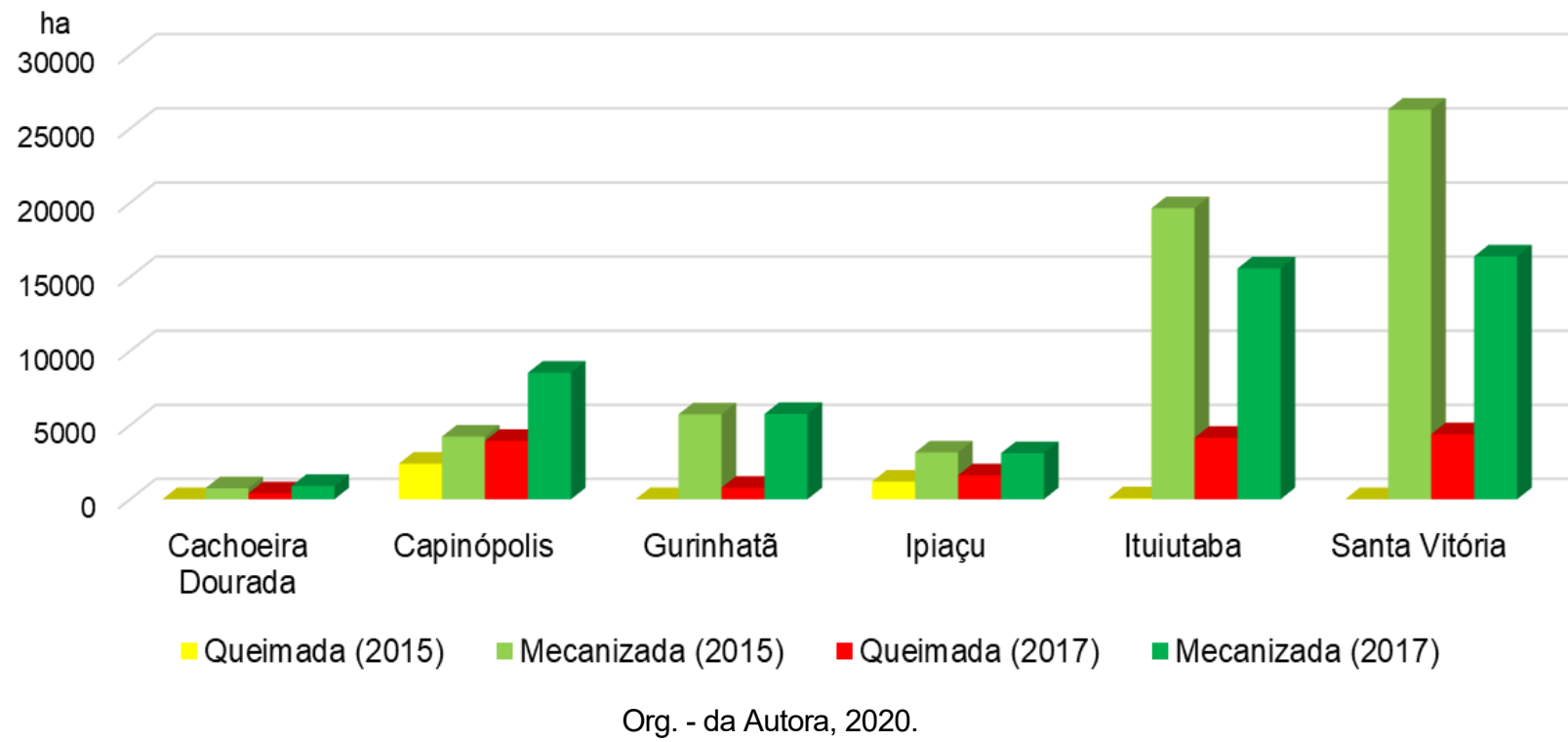

Na microrregião de Araxá, a cana-de-açúcar inexistia nos municípios de Campos Altos, Ibiá, Pedrinópolis, Pratinha e Tapira até o ano de 2017 (Tabela 10 e Figura 16). Uma possível justificativa para tal, pode estar associada ao relevo acidentado dessas áreas, caracterizado como Domínio de Morros e de Serras Baixas, cuja declividade pode variar de 15 a 35 graus, impossibilitando a colheita da cana-de-açúcar e outros cultivos que necessitam de máquinas. Os municípios de Perdizes, Sacramento e Santa Juliana foram os que apresentaram as maiores áreas colhidas (Tabela 10 e Figura16 e 17). 
Figura 16 - Sistema de manejo da cana-de-açúcar na microrregião de Araxá (2015-2017).

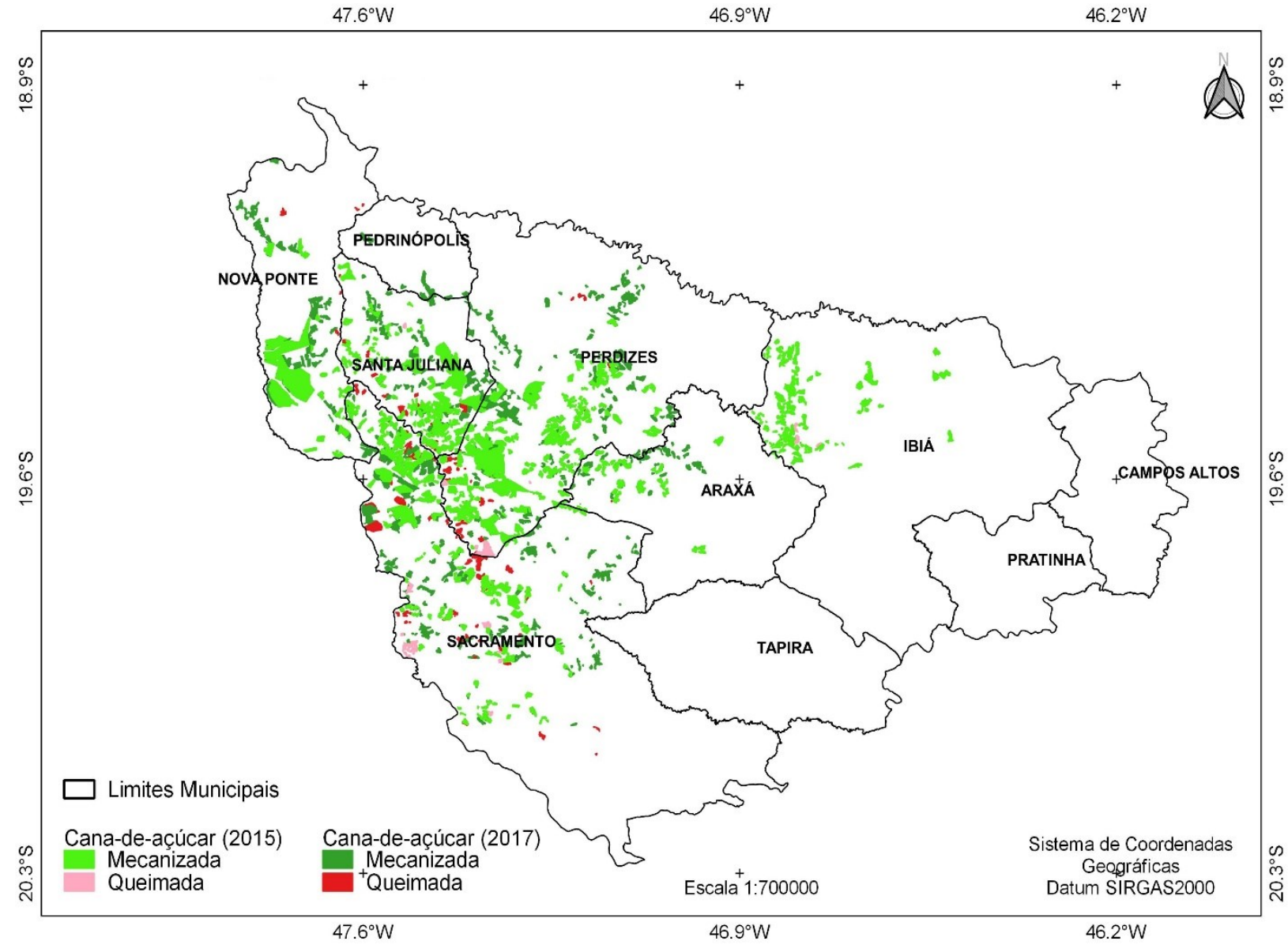

Fonte - da Autora, 2020.

Tabela 10 - Sistema de manejo da cana-de-açúcar (ha) na microrregião de Araxá (2015-2017)

\begin{tabular}{|c|c|c|c|c|c|c|c|c|c|c|}
\hline \multirow{3}{*}{ Municípios } & \multicolumn{5}{|c|}{2015} & \multicolumn{5}{|c|}{2017} \\
\hline & \multicolumn{2}{|c|}{ Queimada } & \multicolumn{2}{|c|}{ Mecanizada } & \multirow{2}{*}{$\begin{array}{l}\text { Total } \\
\text { ha }\end{array}$} & \multicolumn{2}{|c|}{ Queimada } & \multicolumn{2}{|c|}{ Mecanizada } & \multirow{2}{*}{$\begin{array}{c}\text { Total } \\
\text { ha }\end{array}$} \\
\hline & ha & $\%$ & ha & $\%$ & & ha & $\%$ & ha & $\%$ & \\
\hline Araxá & 0 & 0,0 & 2.209 & 100 & 2.209 & 3 & 0,2 & 1.877 & 99,8 & 1.880 \\
\hline $\begin{array}{c}\text { Campos } \\
\text { Altos }\end{array}$ & 0 & 0,0 & 0 & 0,0 & 0 & 0 & 0,0 & 0 & 0,0 & 0 \\
\hline Ibiá & 206 & 3,8 & 5.250 & 96,2 & 5.456 & 0 & 0,0 & 0 & 0,0 & 0 \\
\hline Nova Ponte & 0 & 0,0 & 8.003 & 100,0 & 8.003 & 139 & 1,9 & 7.108 & 98,1 & 7.247 \\
\hline Pedrinópolis & 0 & 0,0 & 0,0 & 0,0 & 0 & 0 & 0,0 & 764 & 100,0 & 764 \\
\hline Perdizes & 547 & 3,2 & 16.310 & 96,8 & 16.857 & 724 & 5,2 & 13.126 & 94,8 & 13.850 \\
\hline Pratinha & 0 & 0,0 & 0 & 0,0 & 0 & 0 & 0,0 & 0 & 0,0 & 0 \\
\hline Sacramento & 710 & 5,7 & 11.799 & 94,3 & 12.509 & 2.741 & 17,4 & 13.043 & 82,6 & 15.784 \\
\hline Santa Juliana & 40 & 0,4 & 10.095 & 99,6 & 10.135 & 1.048 & 13,8 & 6.560 & 86,2 & 7.608 \\
\hline Tapira & 0 & 0,0 & 0 & 0,0 & 0 & 0 & 0,0 & 0 & 0,0 & 0 \\
\hline Total & 1.503 & 2,7 & 53.666 & 97,3 & 55.169 & 4.655 & 9,9 & 42.477 & 90,1 & 47.132 \\
\hline
\end{tabular}

Quanto a colheita da cana queimada, em 2015, esta representou 2,7\% (1.503 ha), ao passo que, em 2017 a microrregião alcançou 9,9\% (4.655 ha), com destaque para o município de Sacramento que obteve a

$\begin{array}{lllll}\text { Caminhos de Geografia } & \text { Uberlândia-MG } & \text { v. 21, n. } 77 & \text { Out/2020 } & \text { p. 263-282 Página } 279\end{array}$


maior área queimada nos dois anos. Em relação a cana-de-açúcar colhida mecanicamente, em 2015, somou $97,3 \%$ (53.666 ha) e em 2017 houve uma queda de 7,2 pontos percentuais em relação ao ano anterior, alcançando 90,1\% (42.477 ha).

Figura 17 - Área colhida (ha) de acordo com o sistema de manejo da cana-de-açúcar na microrregião de Araxá (2015-2017).

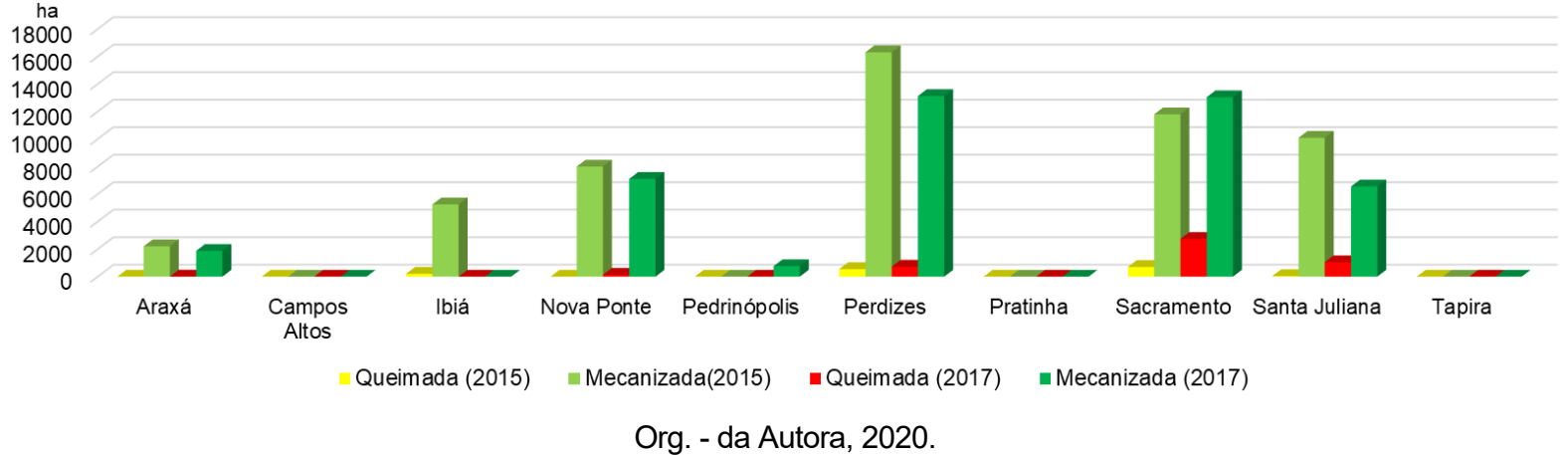

\section{CONSIDERAÇÕES FINAIS}

A metodologia empregada neste trabalho mostrou-se satisfatória para alcançar o objetivo proposto quanto a identificação dos diferentes sistemas de manejo do corte da cana, seja mecanicamente, para a cana cortada crua, ou por meio de queimadas. Os resultados demonstraram decréscimo na área plantada, ou destinada à colheita, que passou de 718.065 ha para 653.740 ha, em 2015 e 2017, respectivamente. Em contrapartida, foi verificado o aumento de 34.231 ha na cana colhida com uso do fogo na pré-colheita.

Em todas as microrregiões houve redução da área mecanizada e incremento das queimadas, com destaque para Frutal, que perdeu 83.929 ha de colheita mecanizada, ao mesmo tempo em que ocorreu aumento de 10.976 ha com uso do fogo, ficando atrás apenas de Ituiutaba, que atingiu 11.588 ha queimados, no recorte temporal analisado. Em termos absolutos, a microrregião de Uberaba é a que possui a maior extensão de área queimada, ao todo foram queimados 23.768 ha, em 2015, e 31.933 ha, em 2017, o que representou um incremento de 8.165 ha. A exceção se aplica as microrregiões de Patos de Minas e Patrocínio pela inexistência do cultivo da cana.

Quanto à constatação do aumento do uso do fogo na Mesorregião (de 7,1\% para 13,1\% no período analisado), é preciso apontar que vários fatores podem estar associados a isso, dentre eles, o longo período de estiagem verificado desde o final do mês maio até meados de outubro de 2017 (CONAB, 2017, p. 48), que pode ter ocasionado queimadas acidentais, ou até mesmo o descumprimento da legislação ambiental sobre o uso do fogo no Estado, que proíbe a prática desde 2014 (Deliberação Normativa n 133, COPAM, 2009). Todavia, somente uma pesquisa aprofundada é capaz de responder fidedignamente essa questão, com base nisso, as pesquisadoras estão testando novas metodologias e buscando fontes de dados confiáveis para elucidar às suas causas.

A queima prévia da cana-de-açúcar visa facilitar a colheita manual ou mecanizada reduzindo os custos na produção. Dentre as dificuldades para eliminação total da prática estão as dificuldades financeiras que o setor enfrenta, no entanto, medidas de prevenção, controle e fiscalização precisam ser mais efetivas no combate às queimadas nos canaviais.

\section{AGRADECIMENTOS}

Ao CNPq e à FAPEMIG, pelo financiamento do projeto de pesquisa, pela concessão da bolsa de mestrado FAPEMIG-12905. 


\section{REFERÊNCIAS}

AGUIAR, D. A.; RUDORFF, B. F. T.; SILVA, W. F. Monitoramento do modo da colheita da cana-de-açúcar no Estado de São Paulo - Brasil por meio de imagens de sensores orbitais em dois anos-safra. Revista SELPER, v. 30, p. 34-43, 2010.

BAATZ, M.; SCHÄPE, A. Multiresolution segmentation: an optimization approach for high quality multi-scale image segmentation. Journal of Photogrammetry and Remote Sensing, v.58, n.10, p. 12-23, 2000.

CONGALTON, R. G., AND GREEN, K. Assessing the accuracy of remotely sensed data: Principles and practices. New York: CRC Press, 2 Ed. 210p. 1957.

COMPANHIA NACIONAL DE ABASTECIMENTO (CONAB). Acompanhamento da safra brasileira: canade-açúcar, Safra 2017/18. Terceiro Levantamento. Brasília, v. 4, n.3, dezembro de 2017. Disponível em< https://www.conab.gov.br/info-agro/safras/cana/boletim-da-safra-de-cana-de-acucar?start=10>. Acesso em 23 set. 2020.

CONSELHO ESTADUAL DE POLÍTICA AMBIENTAL. Deliberação normativa COPAM n 133, de 15 de abril de 2009. Regulamenta a prática da queima de cana-de-açúcar para fins de colheita, e dá outras providências. Disponível em: < http://www.siam.mg.gov.br/sla/download.pdf?idNorma=32595>. Acesso em: 13 jul. 2017.

COSTA, G. H. G.; MASSON, I. S.; ROVIERO, J. P.; MUTTON, M. J. R. Reflexos do processamento de cana-de-açúcar bisada na qualidade do açúcar VHP. Boletim CEPPA, Curitiba, v. 32, n. 2, p. 281-288, jul./dez. 2014. Disponível em: <https://repositorio.unesp.br/bitstream/handle/11449/133650/ISSN19839774-2014-32-02-281-288. pdf?sequence=1\&isAllowed=y>. Acesso em: 16 dez. 2018.

DEBASTIANI, A. B., SOUZA, M.; MARCIELLI, AP. B.S.; SILVA, R. DAL'AGNOL; GUILHERME MOACIR SCHWADE.; LELIS, L.; BOTELHO, M. F. Árvore de decisão aplicada na identificação de áreas de risco de deslocamento: comparação dos métodos J48, Árvores Funcionais e Árvore Aleatória. VIII Colóquio Brasileiro de Ciências Geodésicas. p. 01.2013 Disponível em: $<$ https://www.researchgate.net/publication/291341155_Arvore_de_decisao_aplicada_na_identificacao_de_ areas_de_risco_de_deslizamento_comparacao_dos_metodos_J48_Functional_Trees_e_Random_Tree>. Acesso em 23 jun. 2018.

DIAS, B. A. S.; SCHULTZ, B.; SANCHES, I. D.; EBERHARDT, I. D.; ROSENDO, J. S. Identificação do modo de colheita da cana-de-açúcar em imagens multitemporais Landsat-like. RBC. REVISTA BRASILEIRA DE CARTOGRAFIA (ONLINE), v. 70, p. 527 - 554, 2018. https://doi.org/10.14393/rbcv70n2-45381 https://doi.org/10.14393/rbcv70n2-45381

DIAS, B. A. S.; VICOSO, L. C. B.; ROSENDO, J. S. Análise temporal da expansão da cana-de-açúcar e suas implicações sobre as mudanças de uso da terra na microrregião de Ituiutaba-MG, Brasil, 2018.

FIGUEIREDO, D. Conceitos Básicos de Sensoriamento Remoto. Companhia Nacional de Abastecimento CONAB. Brasília - DF, 2005. Disponível em: <http://www.clickgeo.com.br/wpcontent/uploads/2013/04/conceitos_sm.pdf>. Acesso em: 15 set. 2020.

IBGE. Sistema IBGE de Recuperação Automática - SIDRA. 2018. Disponível: < https://sidra.ibge.gov.br/tabela/5457\#resultado>. Acesso em: 17 de set. 2020.

INPE - Instituto Nacional de Pesquisas Espaciais, 2018. Portal do Monitoramento de Queimadas e Incêndios. Disponível em: <http://www.inpe.br/queimadas>. Acesso em: 22 ago. 2020.

MATSUOKA, J. V.; HAERTEL, V. Investigação do processo de segmentação multiresolução utilizando o critério de ponderação de formas e cores aplicadas às imagens de áreas urbanas de alta resolução espacial do satélite Ikonos. In: Simpósio Brasileiro de Sensoriamento Remoto (SBSR), 13, 2007, Florianópolis. Anais... XIII São José dos Campos: INPE, 2007, p. 589-596. Disponível em: <http://marte.sid.inpe.br/col/dpi.inpe.br/sbsr@80/2006/11.15.11.19/doc/589-596.pdf>. Acesso em: 18 ago. 2018.

NASCIMENTO, R. C. do. Os cafés especiais no Cerrado Mineiro: o circuito espacial produtivo e os círculos de cooperação no município de Patrocínio, MG. Dissertação (Mestrado em Geografia). 237f. Campinas: IG/UNICAMP, 2014. 
RANGEL, R. R. Global projection of Rangel-Um sistema de projeção do globo terrestre sobre um elipsóide. Tese de Doutorado (Computação Aplicada)- INPE. São José dos Campos, p. 221. 2003. Disponível em: <http://mtc-m16.sid.inpe.br/col/sid.inpe.br/jeferson/2004/03.08.16.55/doc/publicacao.pdf>. Acesso em: 05 jun. 2018.

SANCHES, I. Del' ARCO.; ANDRADE, R. G.; QUARTAROLI, C. F.; RODRIGUES, C. A. G. Análise comparativa de três métodos de correção atmosférica de imagens Landsat 5 - TM para obtenção de reflectância de superfície e NDVI In: Simpósio Brasileiro de Sensoriamento Remoto (SBSR), 15., 2011, Curitiba. Anais... XV São José dos Campos: INPE, 2011, p. 7564-7571. Disponível em: <https://www.cnpm.embrapa.br/projetos/mapastore/download/PDF10.pdf>. Acesso em: 15 abr. 2017.

SCHULTZ, B.; FORMAGGIO, A. R.; EBERHARDT, I. D. R.; SANCHES, I. D.; OLIVEIRA, J. C.; LUIZ, A. J. B. Classificação orientada a objeto em imagens multitemporais Landsat aplicada na identificação de canade-açúcar e soja. Revista Brasileira de Cartografia, v.68, p.131-143,2016.

SHIMABUKURO, Y. E. PONZONI, F. J. Mistura Espectral: modelo linear e aplicações. São Paulo: Oficina de Textos, 2017. $127 \mathrm{p}$.

TRIMBLE GEOSPATIAL. Definiens eCognition developer - version 9.0. Munich, Germany. 2014. Disponível em: <https://docs.ecognition.com/v9.5.0/Page\%20collection/eCognition\%20Suite\%20Dev\%20RB.htm> Acesso em 14 mar. 2018.

Recebido em: 20/05/2020

Aceito para publicação em: 11/08/2020 